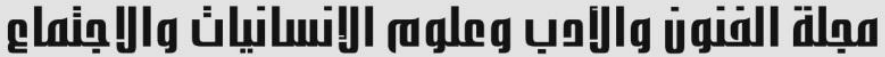

Journal of Arts, Literature, Humanities and Social Sciences www.jalhss.com

\section{الفن المعاصر كمدخل للتعبير عن مرض ألزهايمر (دراسة تحليلية)}

باحث رئيس: غادة عبدالو هاب عبدالله علي طالبة ماجستير في قسم الرسم والقنون عابن عالهي

الايميل: Ghada-nbu@hotmail.com

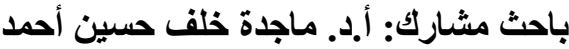

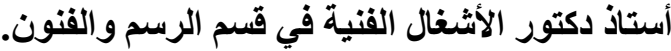
الايميل:tasmagy@hotmail.com

باحث مشارك: أ.د. تبرة جميل طه خصيفان

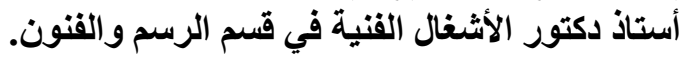

الايميل: tjkhusaifan@uj.edu.sa

كلية التصاميم والفنون - جامعة جدة ـ المملكة العربية السعودية

الملخص

ظهر الفن المعاصر في بدايات القرن العشرين، وقد كان منماثياً مع نهج الفن الحديث، إلا أنه تميّز عنه بعدد من

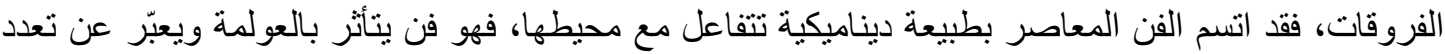

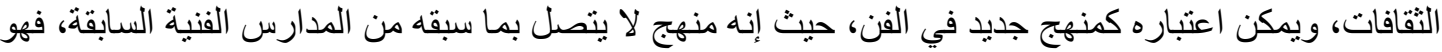

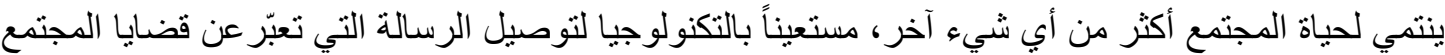
وو اقعه اليومي. ويعد الفن المعاصر احد منابع الفنون لما يحتويه من منظومة فكرية مرتبطة بالمجتمع، فهو يُسنْهُ بالارتقاء في

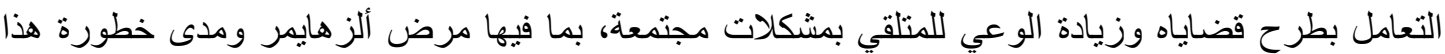
المرض وسر عة إنتشاره وتفاقم خطورته على الأشخاص في سن مبكرة، و علية تتحدد مثكلة البحث في كيفية

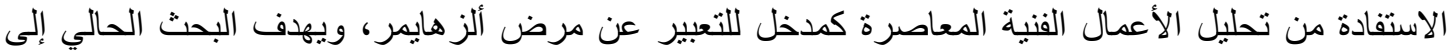

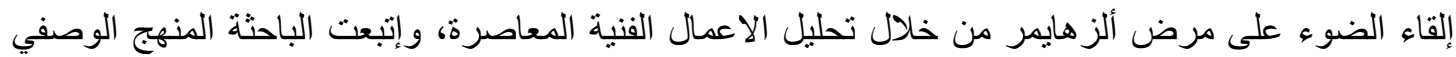

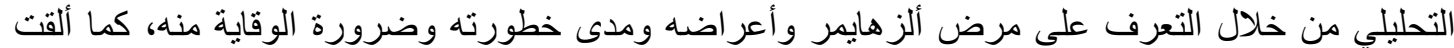

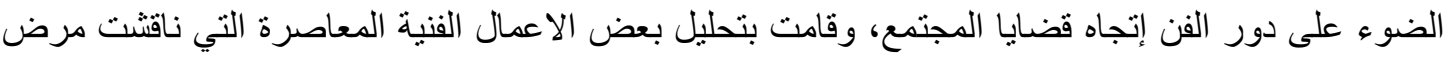

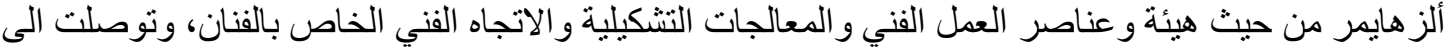

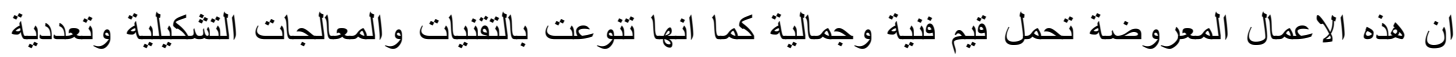

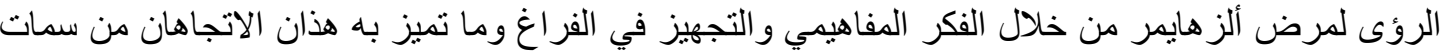
وخصائص ظهرت بصمتها في تحقيق رسالة الفن المعاصر ودوره اتجاه والفر المجتمع.

الكلمات المفتاحية: مرض ألز هايمر، الفن المعاصر ، التعبير، الفن المفاهيمي، فن التجهيز في الفراغ. 


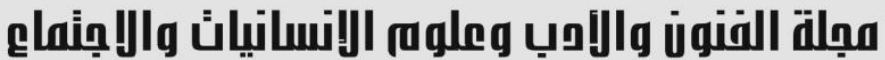

Journal of Arts, Literature, Humanities and Social Sciences www.jalhss.com

\section{Contemporary Art as an Access To the expression about Alzheimer's disease (Analytical Study)}

\author{
Ghada Abdalwahab Abdullah Ali \\ Ghada-nbu@hotmail.com
}

\author{
Prof. Majedah Khalaf Hussein Ahmad \\ tasmagy@ hotmail.com
}

\author{
Prof. Tebra Jameel Taha Khusifan \\ tjkhusaifan@uj.edu.sa
}

College of Art and Design - University of Jeddah - Kingdom of Saudi Arabia.

\begin{abstract}
Contemporary art is one of the sources of art because it contains an intellectual system linked to society, It contributes to the advancement of dealing with its issues and raising the awareness of the recipient about the combined problems, Including Alzheimer's disease, the severity of this disease, the speed of its spread and its aggravation of danger to people at an early age, so the research problem is determined in how to benefit from the analysis of contemporary artworks as an introduction to the expression of Alzheimer's disease, The current research aims to shed light on Alzheimer's disease through an analysis of contemporary artworks, and the researcher followed the descriptive analytical approach by identifying Alzheimer's disease, its symptoms, its severity and the need to prevent it, and also shed light on the role of art in the direction of community issues, She analyzed some contemporary artworks that discussed Alzheimer's disease in terms of the body and elements of artwork and plastic treatments and the artist's artistic direction, and concluded that these presented works carry artistic and aesthetic values as they diversified with techniques, plastic treatments, and plurality of visions of Alzheimer's disease through conceptual thought and processing in a vacuum And what distinguishes these two trends are features and characteristics that have made their mark in achieving the mission of contemporary art and its role towards society.
\end{abstract}

Keywords: Alzheimer's disease, Contemporary Art, Expression, Conceptual art, Installation Art. 


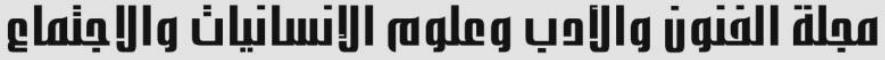

Journal of Arts, Literature, Humanities and Social Sciences www.jalhss.com

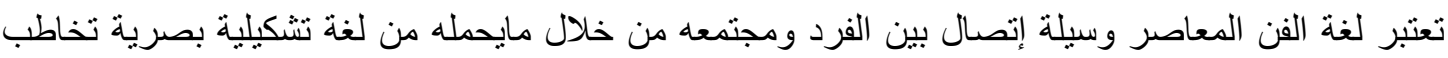

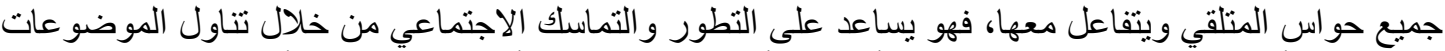

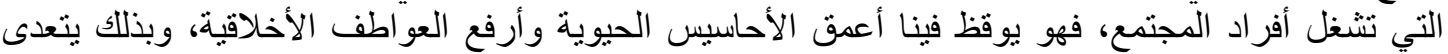

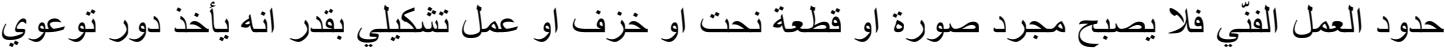

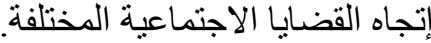

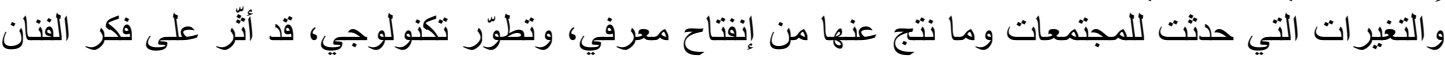

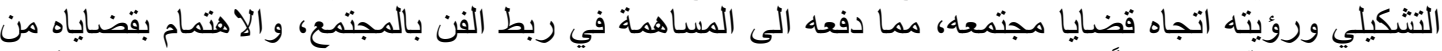

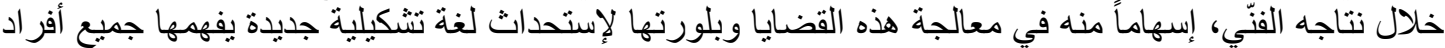

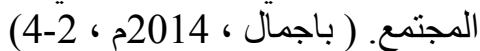

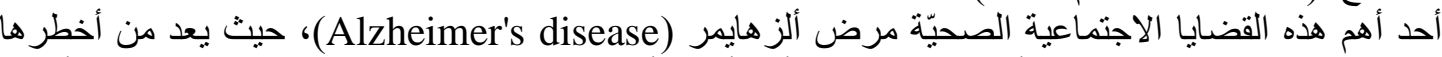

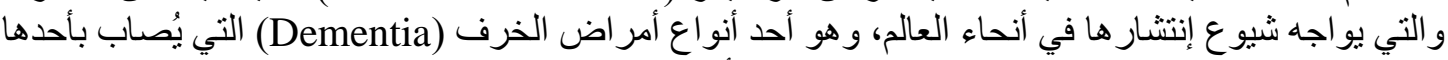

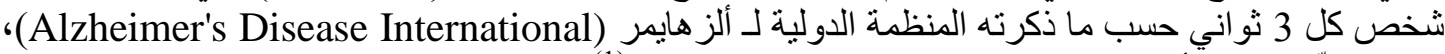

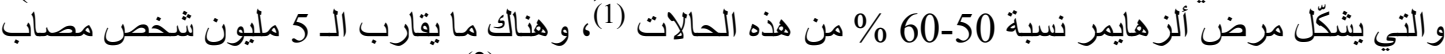

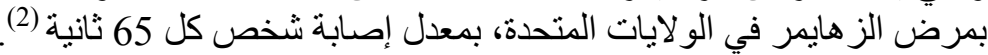

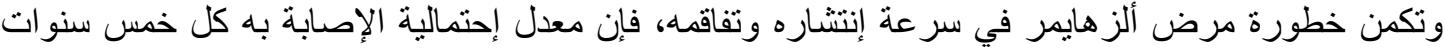

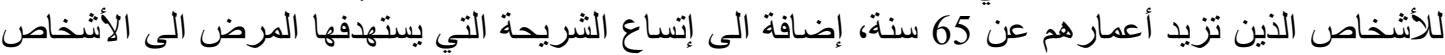

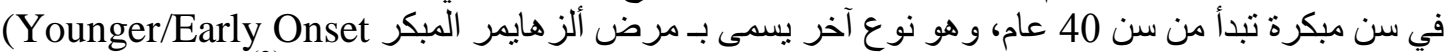

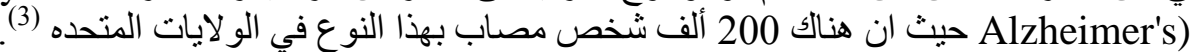

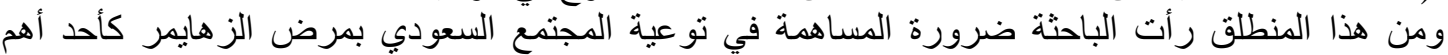

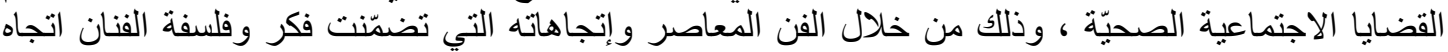

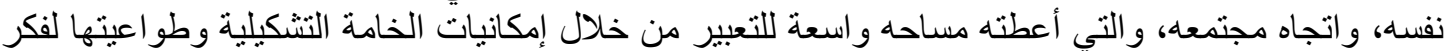

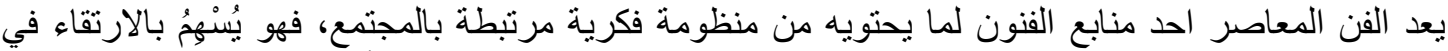

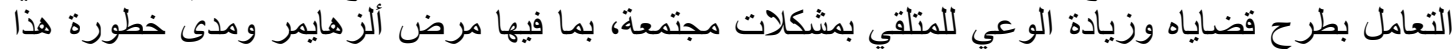
المرض وسرعة إنتشاره وتفاقم خطورته على الأشخاص في سن مبكرة، وعلية تتحدد مشكلة البحث في التسائل فئل فئل كيفية الاستفادة من تحليل الأعمال الفنية المعاصرة كمدخل للتعبير عن مرض ألزهايمر.

\section{فروض البحث يتضمن البحث على البح الفرض الآنه} تفترض الباحثة انه يمكن الاستفادة من تحليل الاعمال الفنية المعاصرة كمدخل للتعبير عن مرض ألزهايمر.

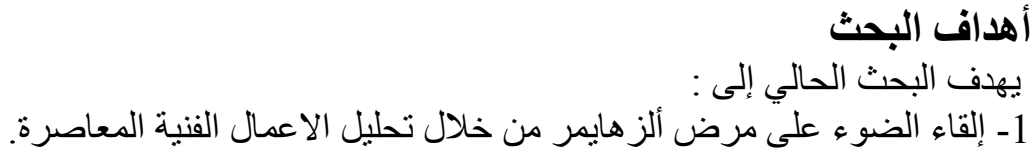




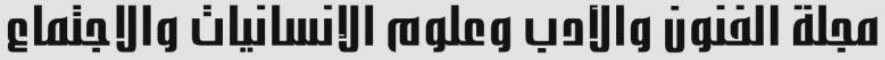

Journal of Arts, Literature, Humanities and Social Sciences www.jalhss.com

2-التعريف بمرض ألز هايمر ومدى خطورته على الفرد و المجتمع وضرورة الوقاية منه.

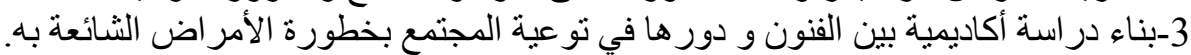

\section{مصطلحات البحث}

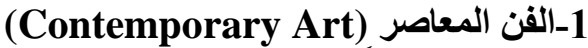

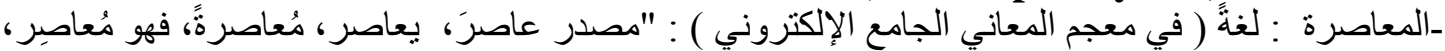

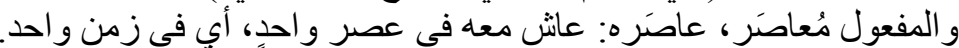

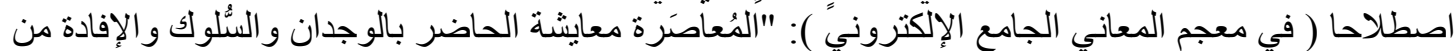

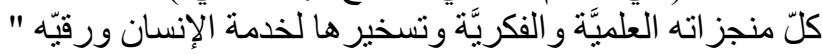

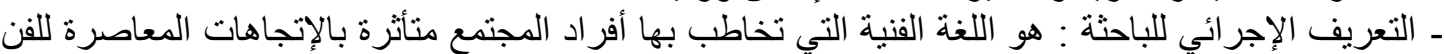

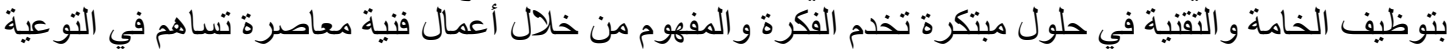
بمرض ألز هايمر.

(Expression ) التعبير الزهاير (2)

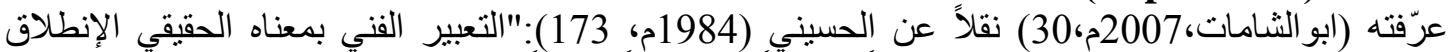

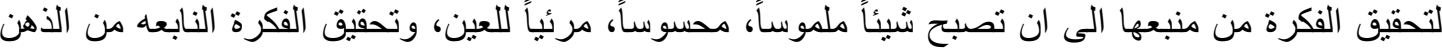

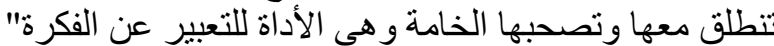

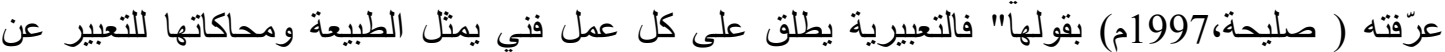

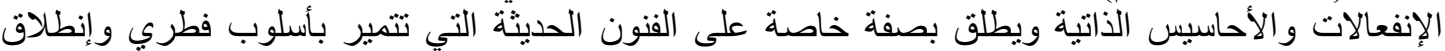
وتغيير وتبديل في العناصر أو الأشكال الطبيعية لإيجاد تأثير الات إنفعالية".

3- مرض ألزهايمر (Alzheimer's disease)

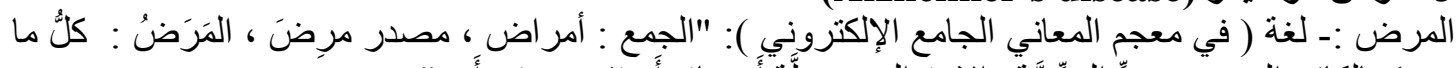

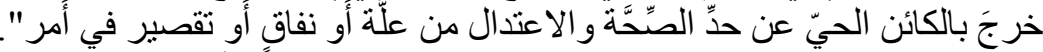

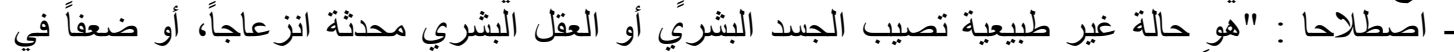

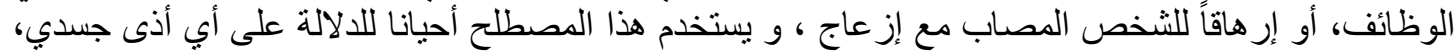

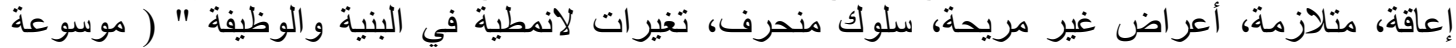

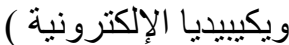

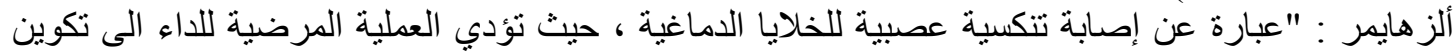

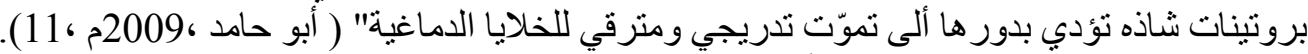

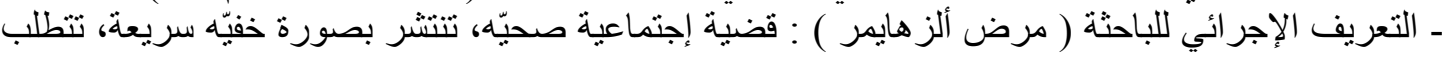

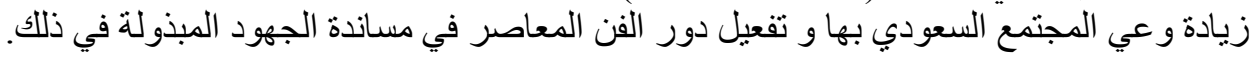




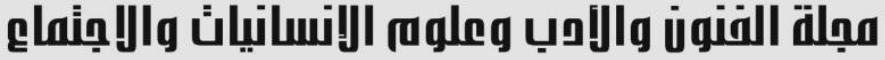

Journal of Arts, Literature, Humanities and Social Sciences www.jalhss.com

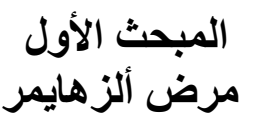

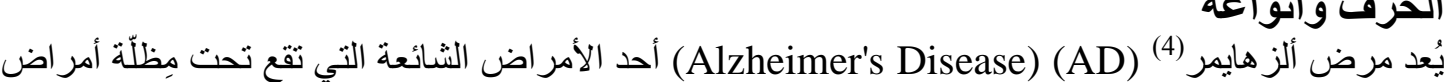

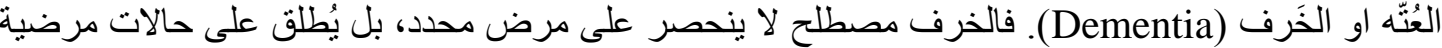

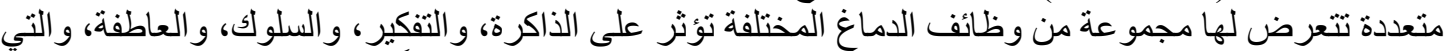

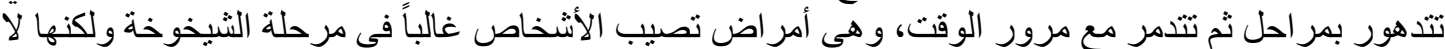

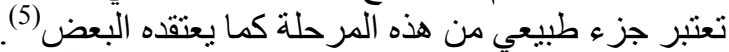

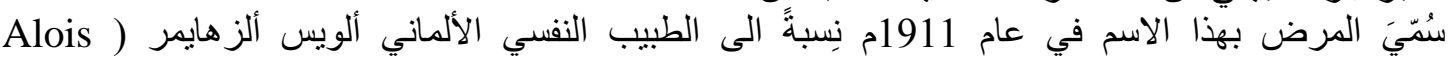

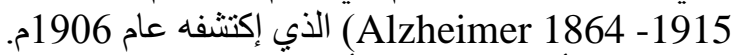

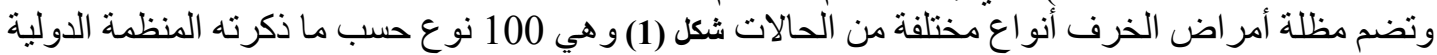

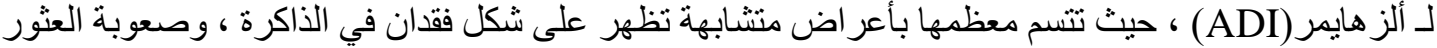

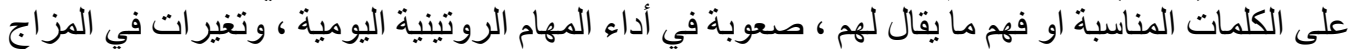
و الثخصية. وتختلف من حيث التغير ات والتكتلات التي تحدثها الحالة المرضية في الدماغ التية ، و هي كالآتي :

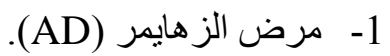

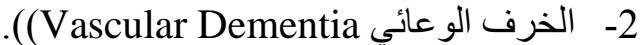

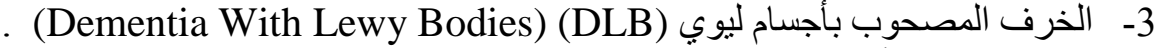

4- الخرف الجبهي أو الصدغي (Frontotemporal Dementia) ( FTD). 5- الخرف المتعدد (Mixed Dementia). 6- مرض باركينسون (Parkinson's Dieases).

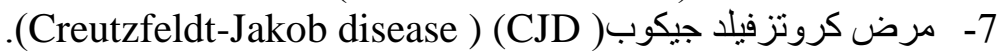
8- استسقاء الضغط الطبيعي (Normal pressure hydrocephalus).

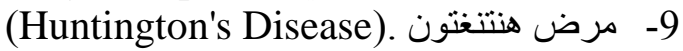
10- متلازمة فيرنيك كورساكوف (Wernicke-Korsakoff Syndrome).

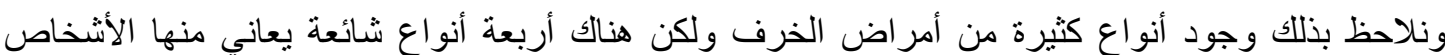

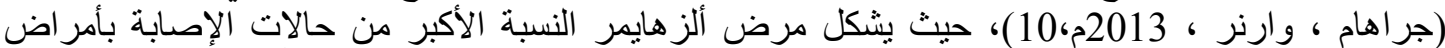

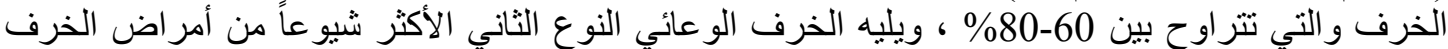

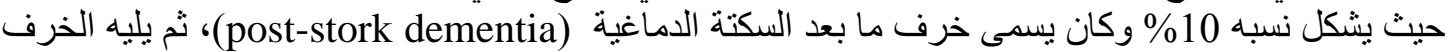
المصحوب بأجسام ليوي، أما النوع الرابع فهو الخرف الجبهي أو الصدغي والذي الذي تتأثر به المناطق الأمامية

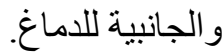




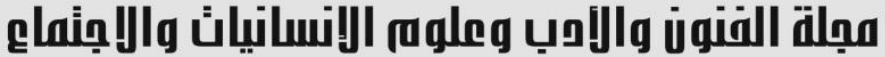

Journal of Arts, Literature, Humanities and Social Sciences

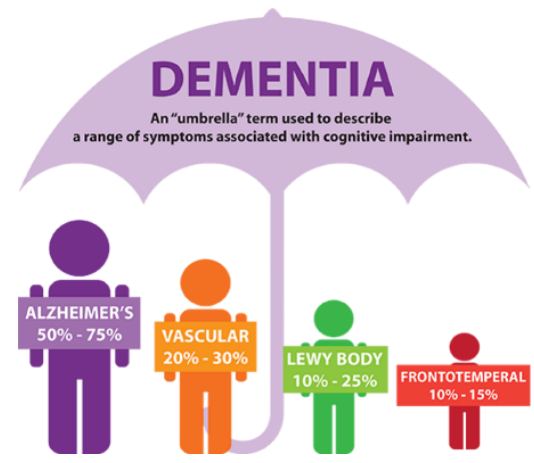

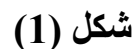

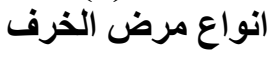

\section{https://www.dfwsheridan.org/types-dementia}

\section{مفهوم مرض ألزهايمر وأنواعه}

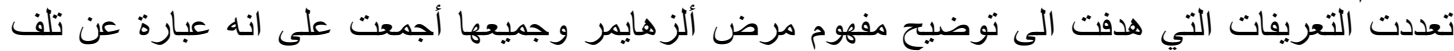

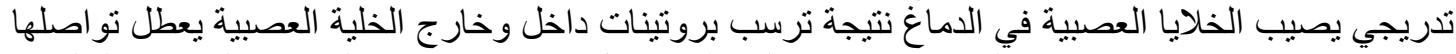

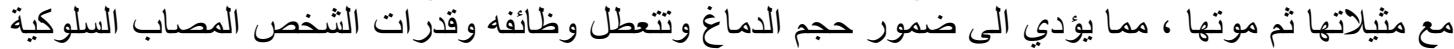
و المعرفية و الإدر اكية.

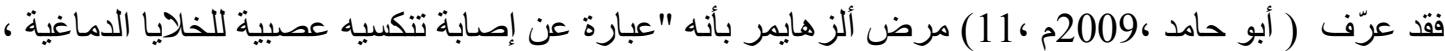

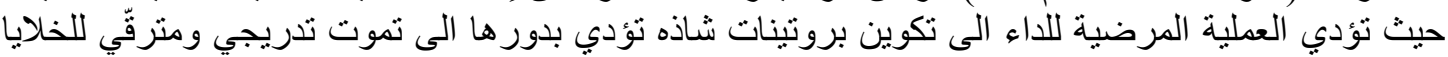

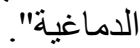

وقد توصلت الباحثة الى ان هناك نو عان من مرض ألز هايمر حسب عو امل الإصابة به :

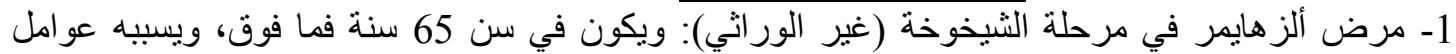

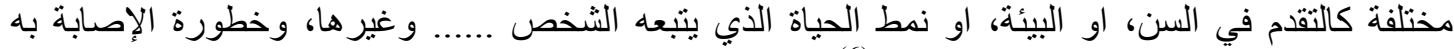

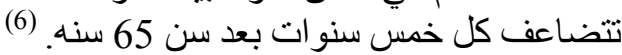
2-مرض ألز هايمر المبكر (EOAD)(Younger/Early Onset Alzheimer's)(وراثي) (7):ويسمى أيضاً

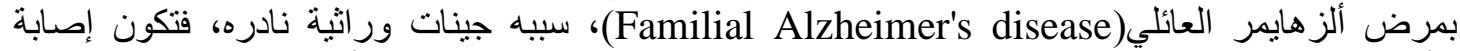

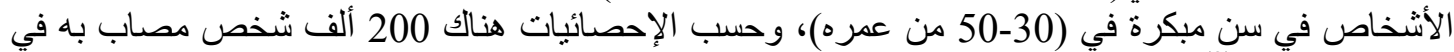

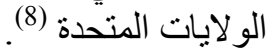

\section{الإحصائيات المتعلقة بمرض ألزهايمر}

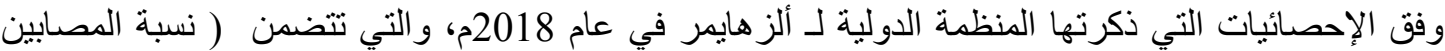

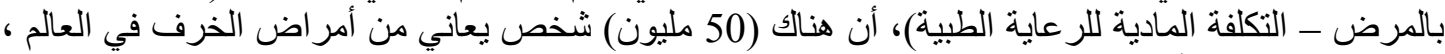

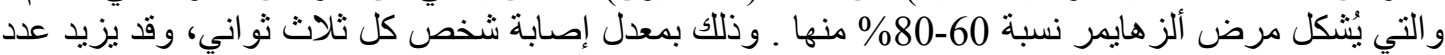

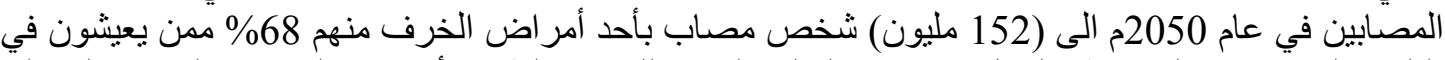

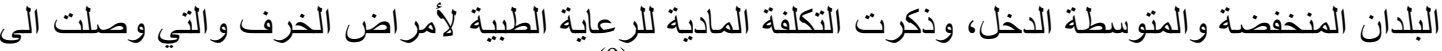

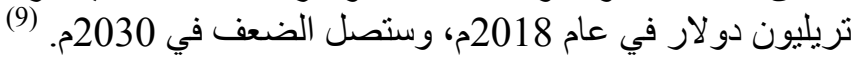




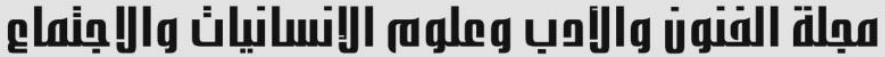

Journal of Arts, Literature, Humanities and Social Sciences www.jalhss.com

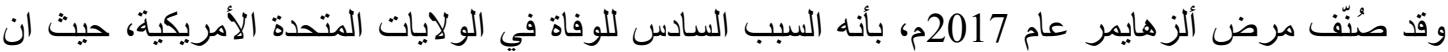

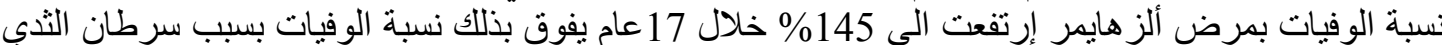
و البروستاتا. (10)

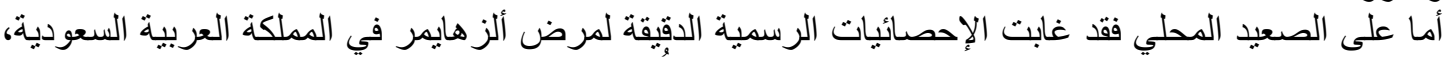

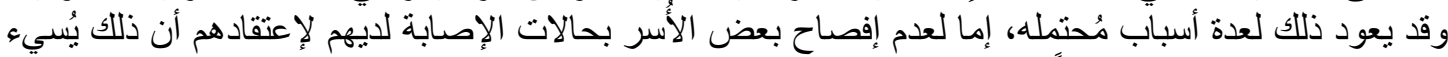

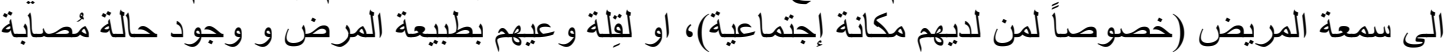

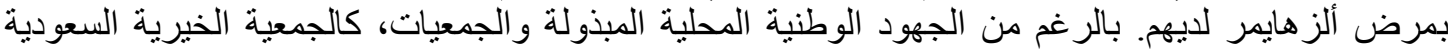

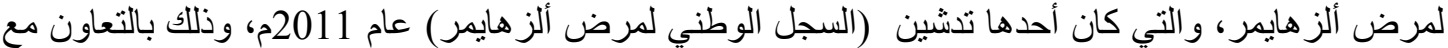

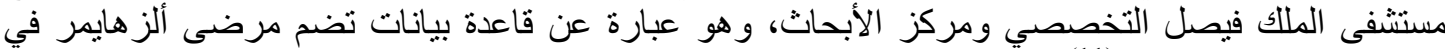

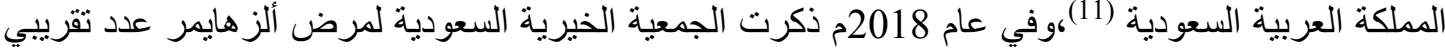

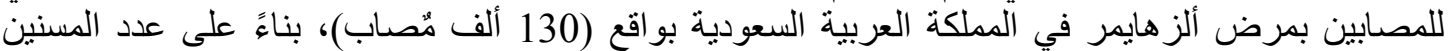

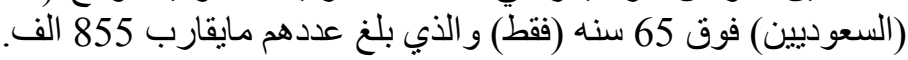

آلية حدوث مرض ألزهايمر عند الإصابة بمرض ألزهايمر يحدث تلف في النسيج الدماغي سبيه تلف الخلايا العصبية نتيجة تعرقل عملية

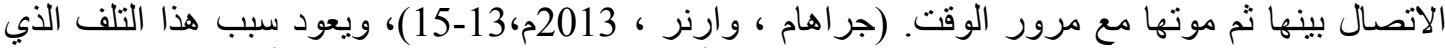
يحدث للخلايا العصبية ويؤدي الى تغير ات في السمات الأساسية للدماغ اللى تكوّن مركبين أساسيين هما : الثكل

1- لويحات شيخية ( Plaques) : وهي عبارة عن تر اكم لقطع من بروتين شاذ في الفر اغات بين الخلايا

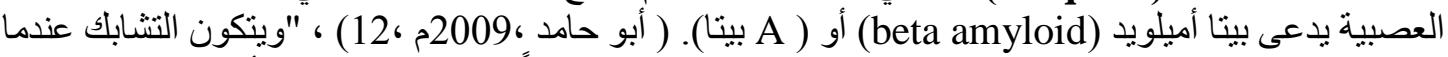

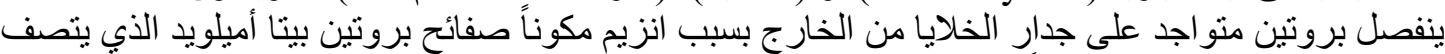

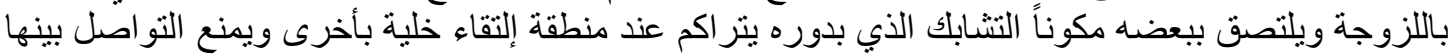

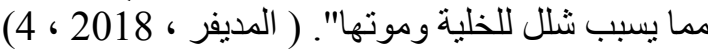

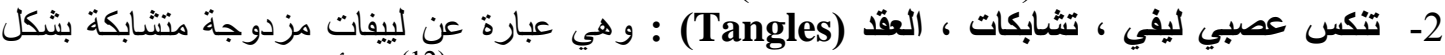

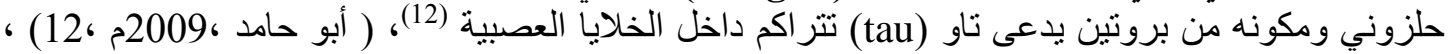

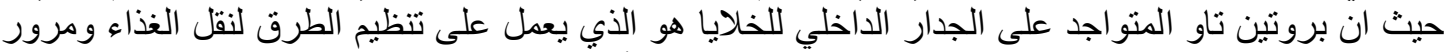

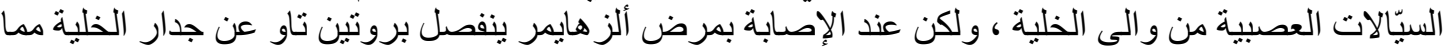

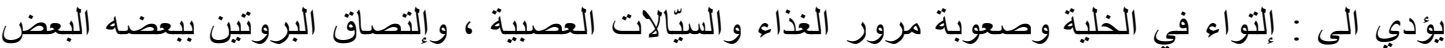

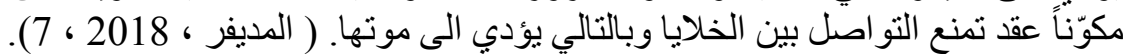

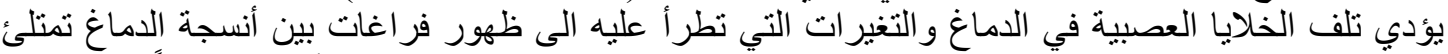

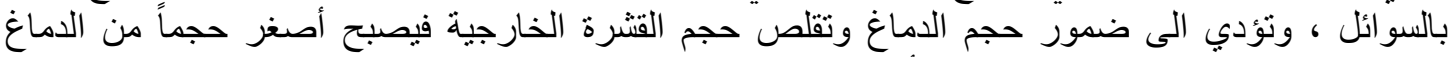

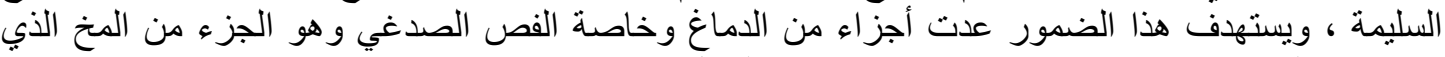
تخزن فيه الذاكرة. (جر اهام ، وارنر ، 2013م،14) الشكل (3). 


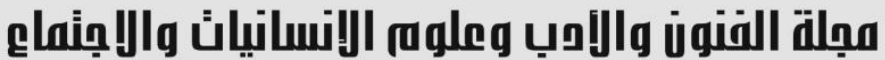

Journal of Arts, Literature, Humanities and Social Sciences www.jalhss.com

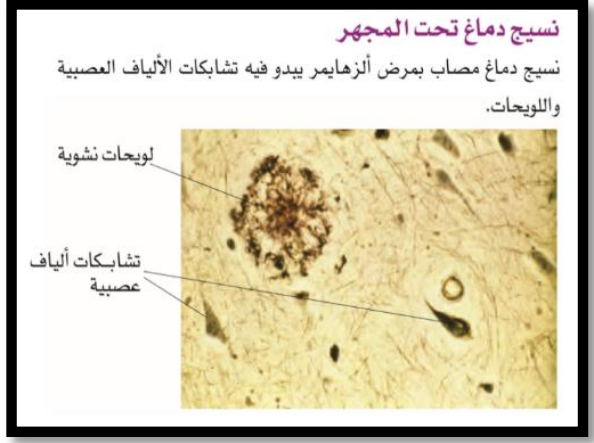

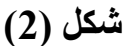

صورة مجهرية لنسيج الدماغ تظهر فيه اللويحات والتشابكات

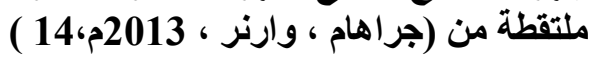

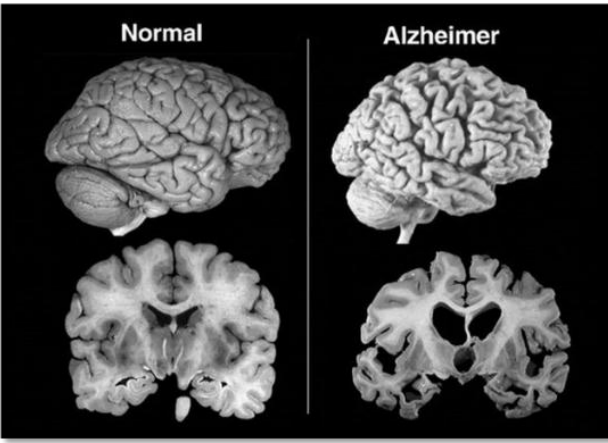

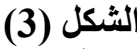

ضمور حجم الاماغ لمريض ألزهايمر وتلف أجزاءه وتآكلاهها

/http://meucerebro.com/cerebros-resistentes-ao-mal-de-alzheimer

أعر اض مرض ألزهايمر

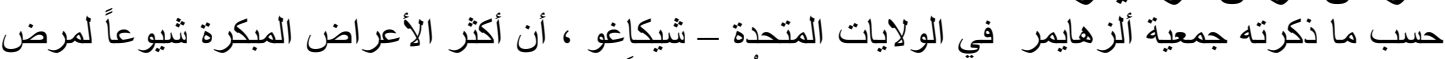

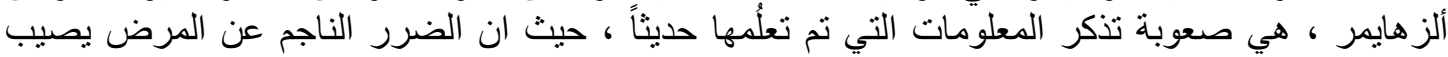

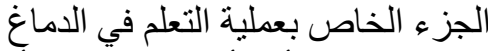

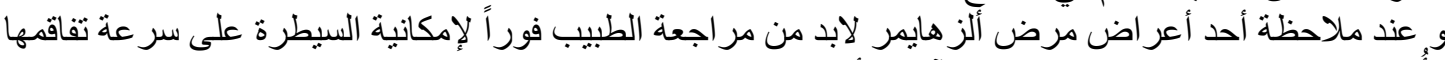

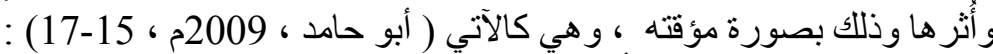

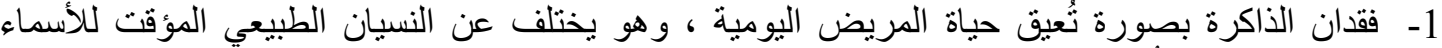

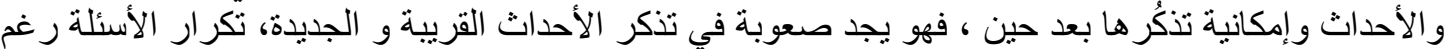

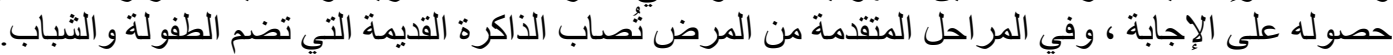

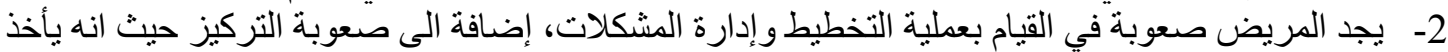

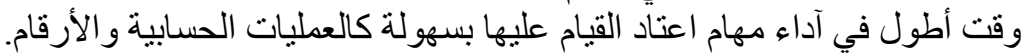

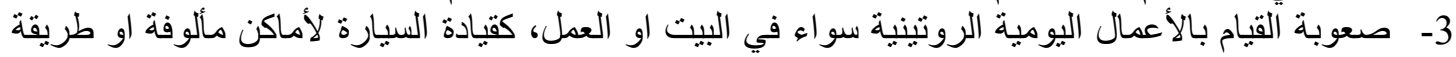




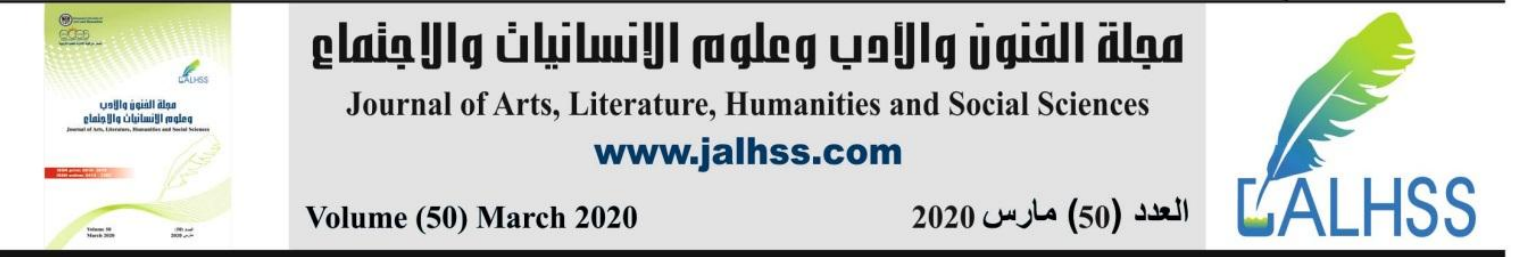

4- تشوش ذهني في المكان او الزمان حيث يفقد القدرة على التعرف على التو اريخ و الأيام ، او فصول السنة ،

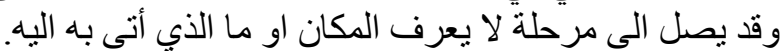

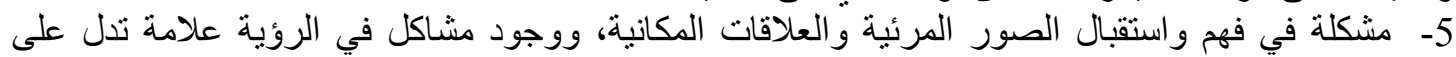

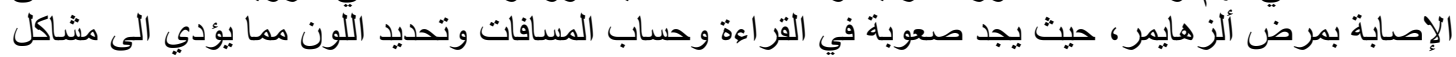

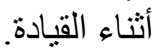

6- اضطر اب في اللغة وصعوبة التدفق الكلامي، حيث يو اجه صعوبة في اختبار المصطلحات وتسمية الأشياء،

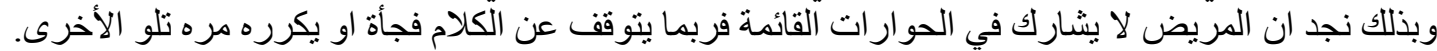

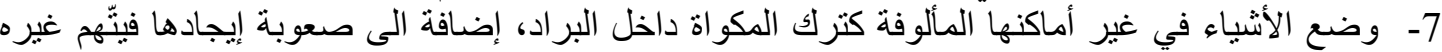

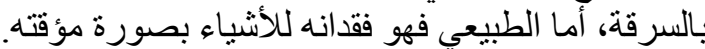
8- انعدام سدادة الر أي وإطلاق الأحكام وتغيرات في اتخاذ القرارات، كاتخاذ قرار ات ماليه خاطئة و إهمال نظافتهم الشخصية و هندامهم. 9- العزلة الاجتماعية وعدم مشاركته للفعاليات في المجتمع وبيئة العمل و العائلة كزيارة الأهل والأصدقاء،

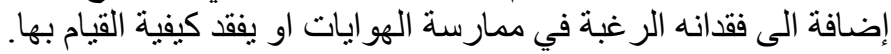

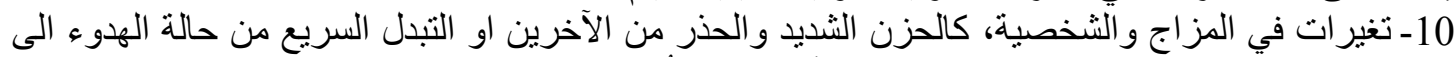

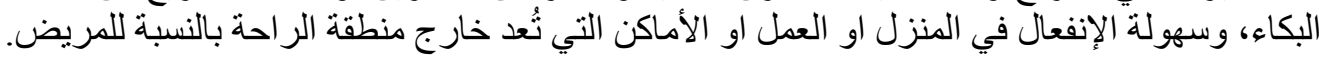

\section{تشخيص مرض ألزهايمر وعلاجه}

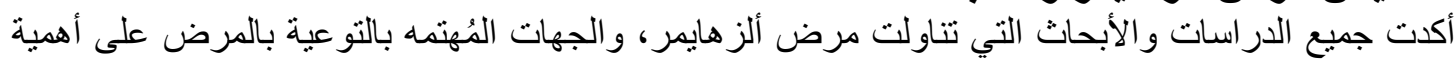

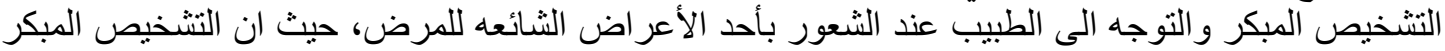

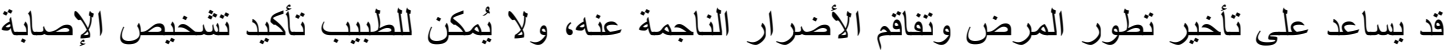

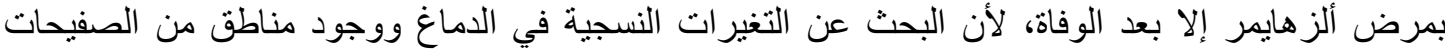

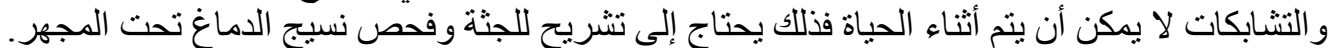

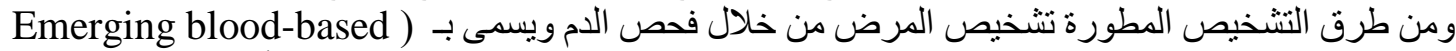

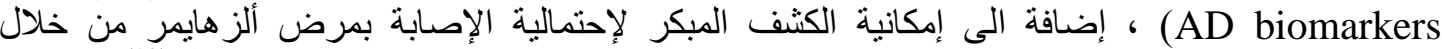

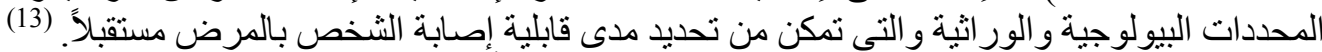

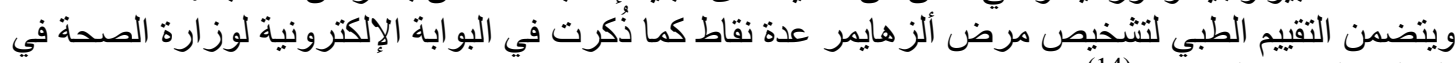
المملكة العربية السعودية (14): الفيبة الطبية

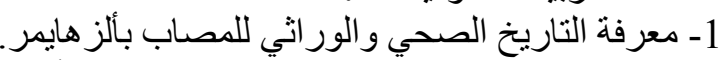

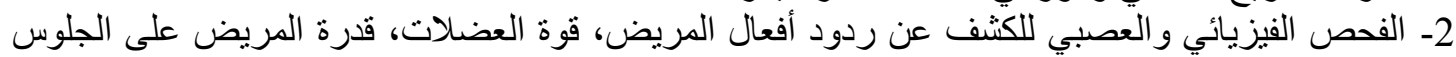
على الكرسي و المشي في الغرفية، التو الفي الفن، وفحص حاستي السمع و البصر.

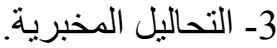

4- عمل أنشعة على منطقة الدماغ (أنشعة مقطعية، أشعة رنين مغناطيسي)".

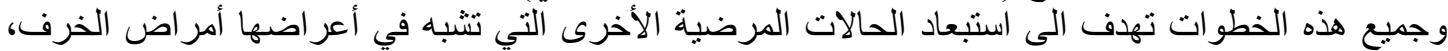

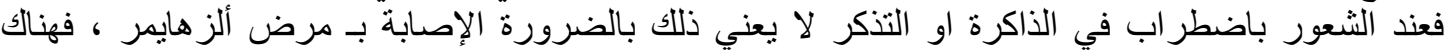

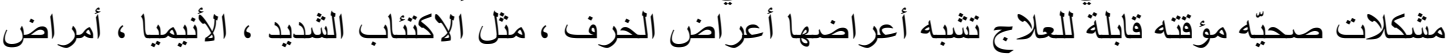

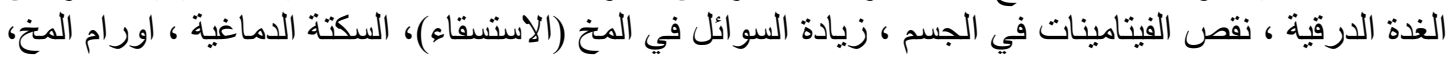

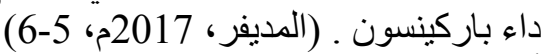

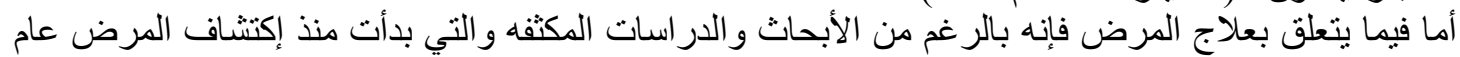

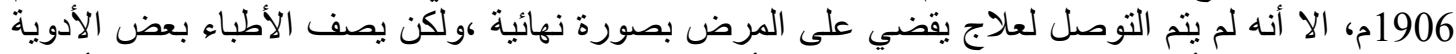

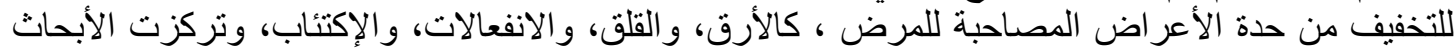

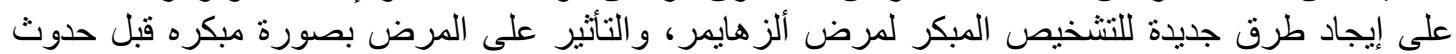
التلف الدماغي و الذي لا بمكن السيطرة عليه (15). 


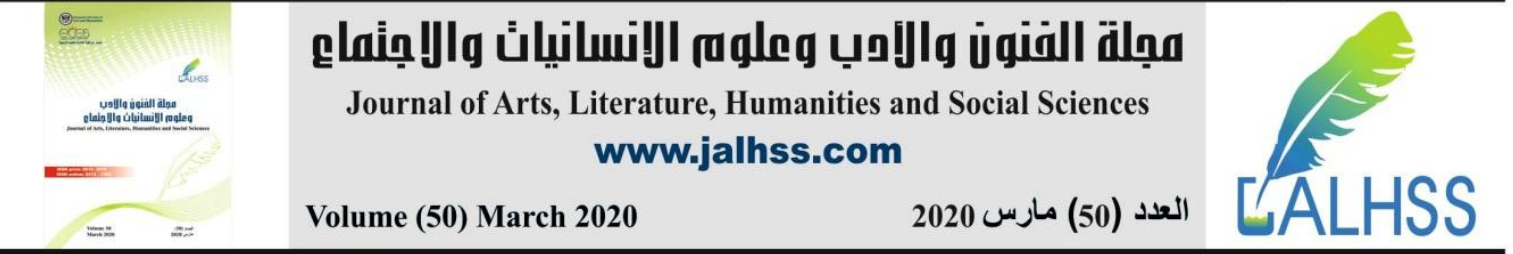

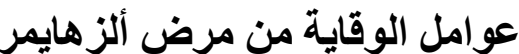

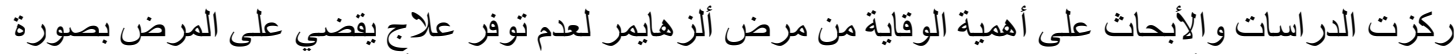

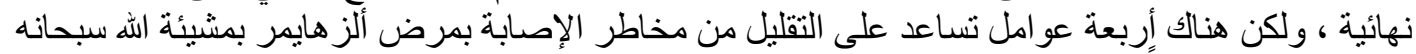
وتعالى ، وهي كالآتي : 1- السيطرة على الأمر اض الفي المزمنة ، كأمر اض القلب ، وارتفاع ضغط الدم ، الكوليسترول ، أمر اض السكري

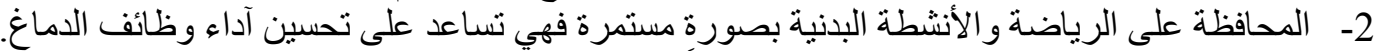

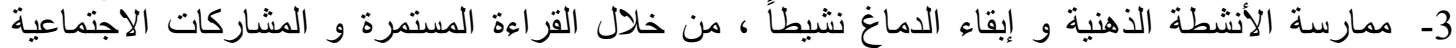

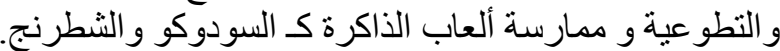

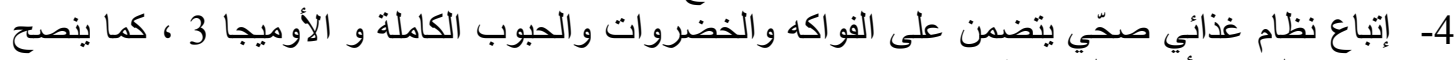

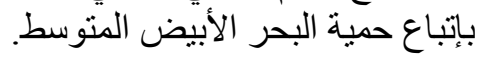

$$
\text { الفبحث الثاني }
$$

مفهوم الفن المعاصر (Contemporary Art)

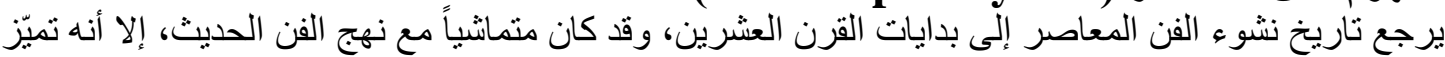

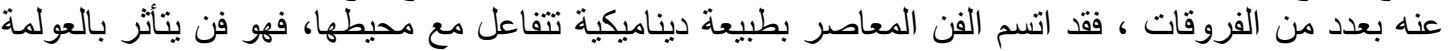

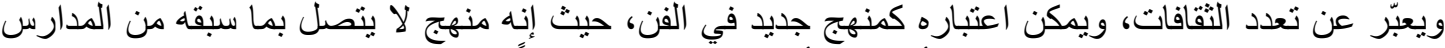
الفنية السابقة، فهو ينتمي لحياة المجتمع أكثر من أي شيء آخر، مستعيناً بالتكنولوجيا لونيا لتوصيل الرسالة التي تعبّر عن قضايا المجتمع وو اقعه اليومي.

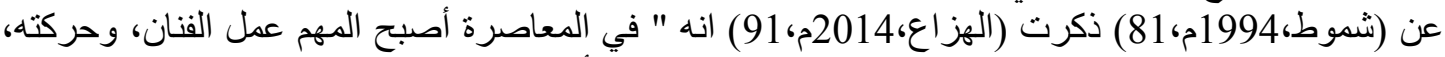

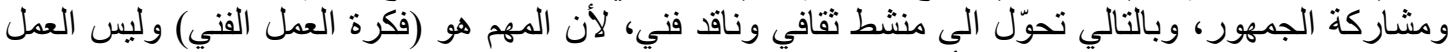
بحد ذاته. وهكذا يتم الخلط بين عدة أنظمة فنية في العمل الواحد..(نحت- عمارة- رسم - مسرح- موسيقى - مونى تصوير فوتوغر افي- حفر- طباعة- رقص- نشاط- سياسة )، مما حول العمل الى استعر اض سمعي- بصريحركي".

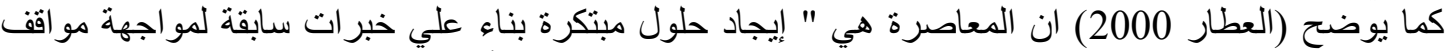
تفرضها متغيرات جديدة وينطبق هذا المفهوم علي الابداع الفني، حيث أنه استجابة لمثيرات معينة ، وتختئلف

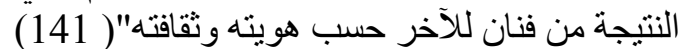
ومما سبق تتضح أهمية المعاصرة والاتجاهات الفنية الحديثة حيث انها ساهمت في تكوين فكر الفنان ومفاهيمه التشكيلية التي قد تحقق إثر اء فنيا في التعبير تشكيلياً بالخامات التهات المتعدده.

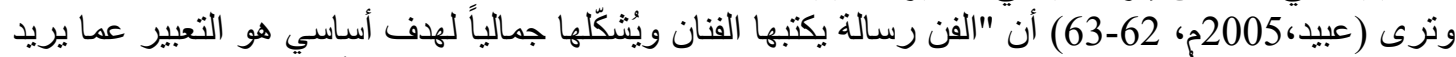

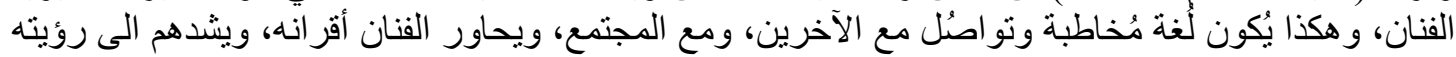

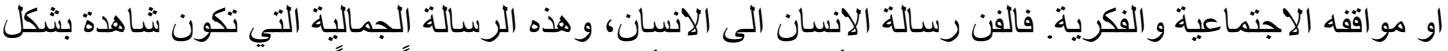

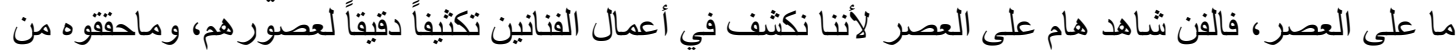

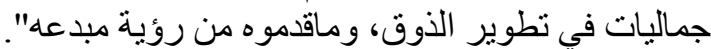

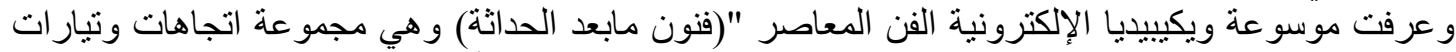

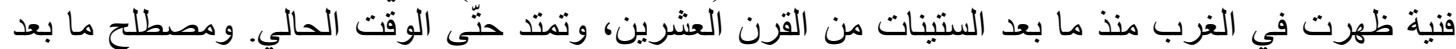

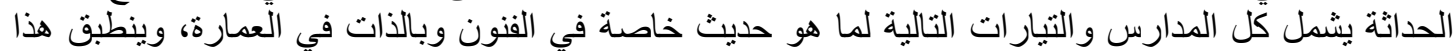
اللفظ على حركة تناهض ما يعرف "بالحديث"، ويتداول مصطلح هولح الفن المعاصر في مجال الفنون التنكيليّة كمقابل أو مر ادف لمصط كلةح ما بعد الحداثة (عمارة) المتخصص في في مجال العمارة" (16). 


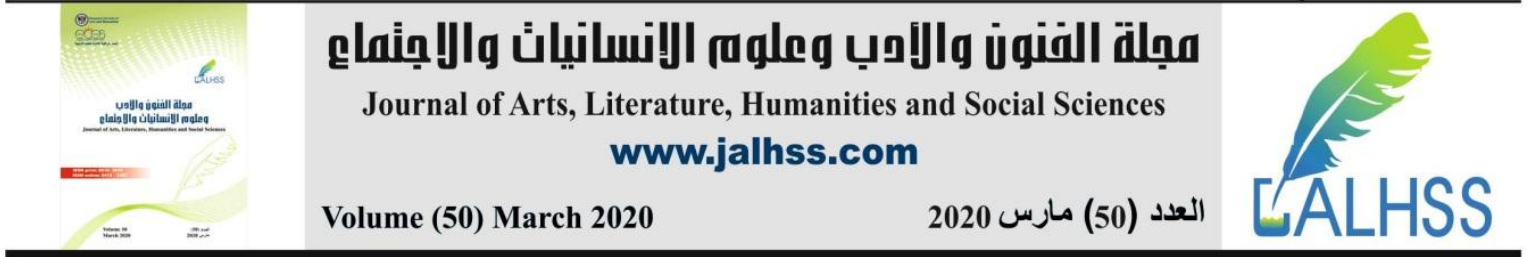

سماث الفن المعاصر من خلال تأثر العمل الفنّي بالإتجاهات الفنية المعاصرة والتئ التطور العلمي و التكنولوجي و إستحداث صياغات

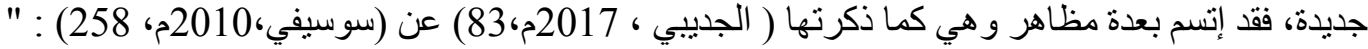
إختلاط التجسيم بالتسطيح في معالجة الثكل، والتركيز على التهي الأشكال ثنلاثية الأبعاد سو اء الخارجة من

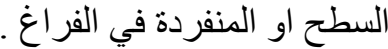

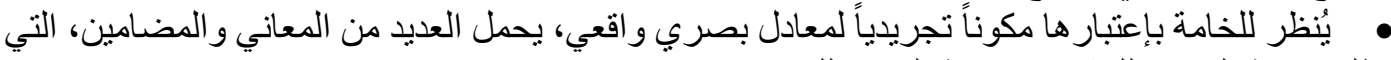
تطلق حرية التفسير للمشاهد وحرية التعبير هاعير للفنان.

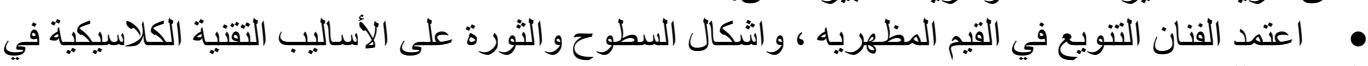
الخامة و اللون. تعدد الوظائف للمشنولة الفنّية غر ابة الأشكال وبعدها عن الأشكال الكلاسيكية المألوفة للتأكيد على القيمة.

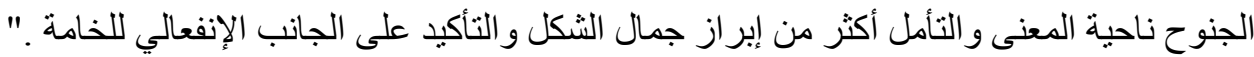

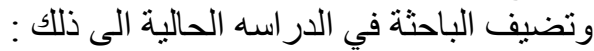
تتوع الخامات في العمل الفني بالتوليف بين التقليدية منها و المستحدثة الغير مألوفة. تعبيرية الخامات المستخدمة في العمل الفني ، بحيث تخدم الفكرة المر اد إيصالها للتلقي. تتوع التقنيات المستخدمة لمعالجة الخامات وتطويعها لتحفيق الهدف من الته العمل الفني. تنوع طرق عرض الأعمال الفنية وفق ماتقتضيه الأساليب في الاتجاهات الفنية المعاصرة.

\section{التعبير في الفن المعاصر}

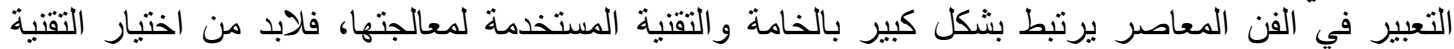

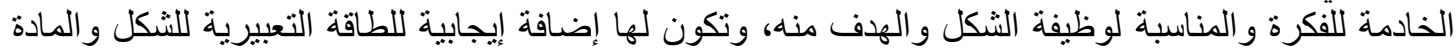

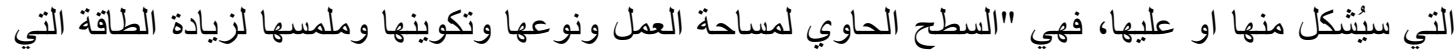

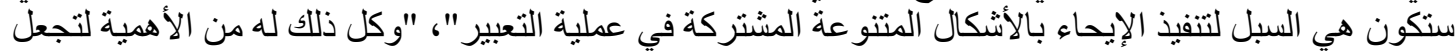

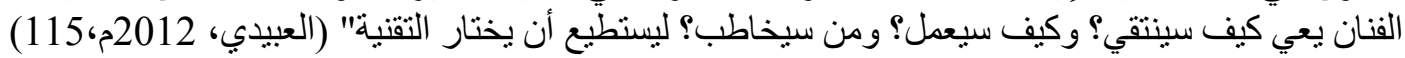

\section{أنواع التعبير في الفن المعاصر}

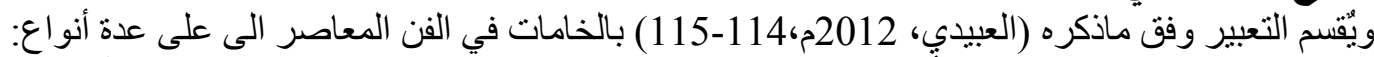

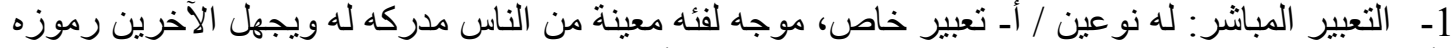

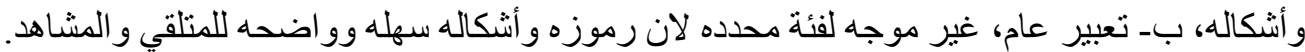

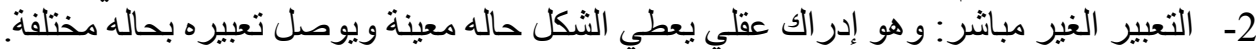

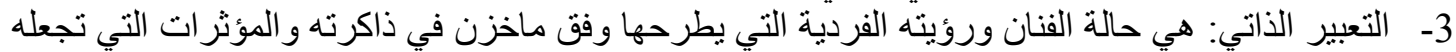
يستحدث تعبيره عن حالثنه تللك ليستلمها المتلقي.

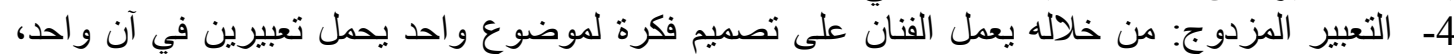

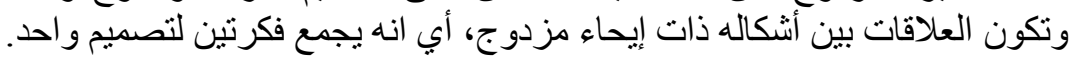

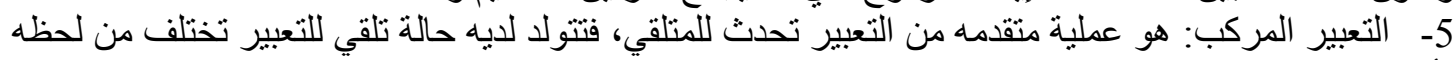
لأخرى وذللك بسبب العوائق الثقافية له. له.

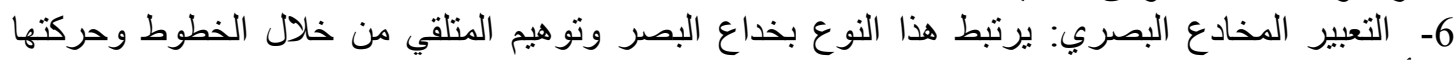
والألوان ودرجات ظلها التي تكون غير موجودة في الحقيقة.

اتجاهات الفن المعاصر (ما بعد الحداثة ) تأثر الفن بالتطورات الحديثة وظهرت إتجاهات ومداه التهارس فنبة معاصرة تندرج تحت مصطلح (فنون مابعد

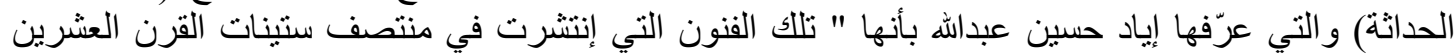




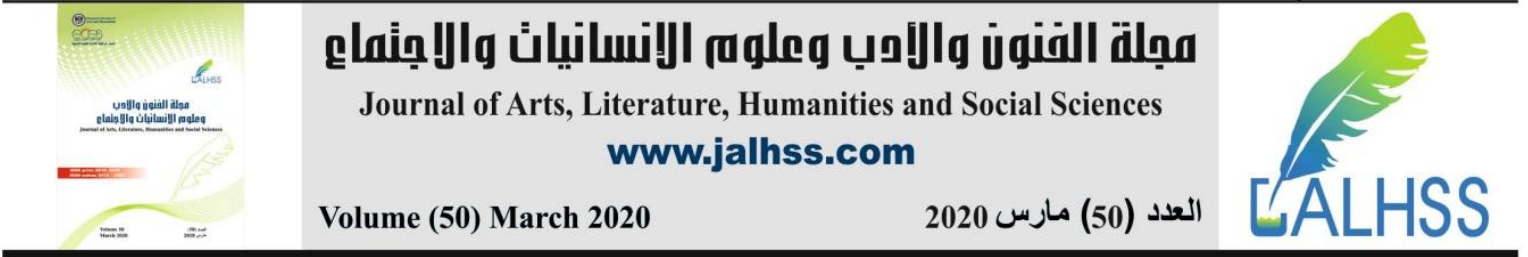

كنفي وتجاوز لأطروحة الحداثة، وهي تحمل في طياتها سمات ومبادئ تميز ها عن غيرها من الفي الفنون السابقة،

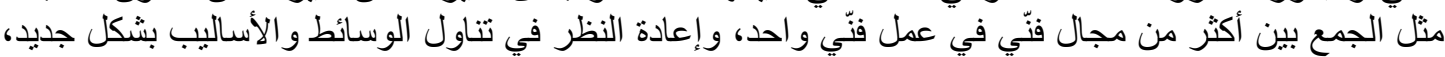

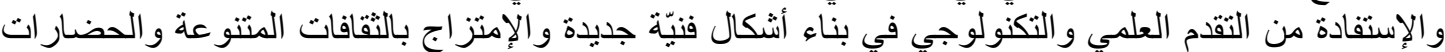

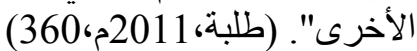

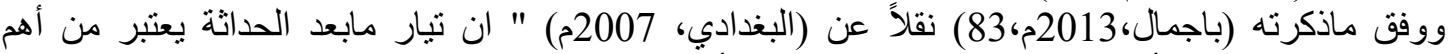

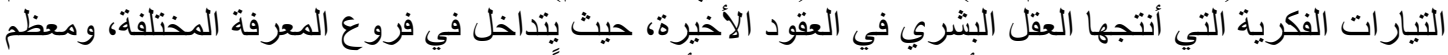

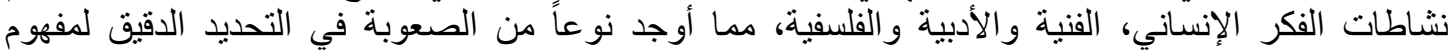

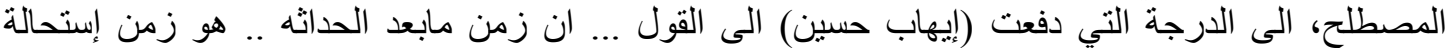

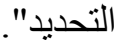
وقد "افصحت الرؤى و المفاهيم الحديثة للحياة و المجتمع، في بدايات القرن الحادي و العشرين عن فنون معاصرة،

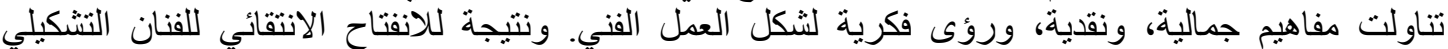

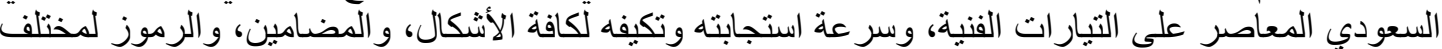

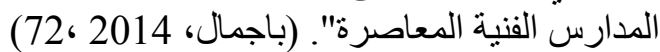

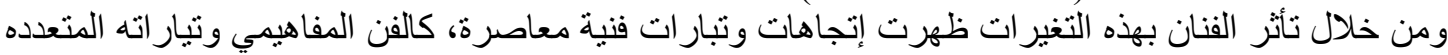

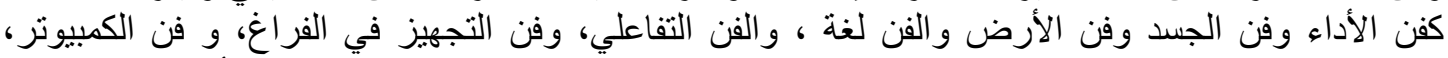

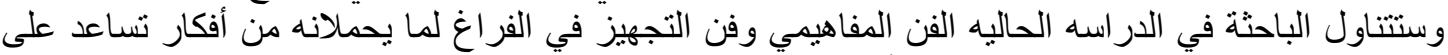
إيصال الرسائل التوعوية البصرية بمرض النه الزية هايمر.

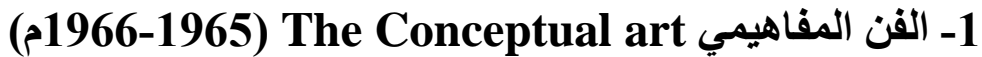

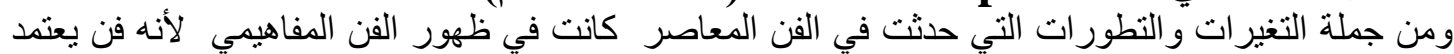

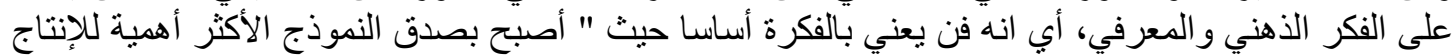

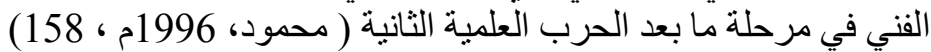

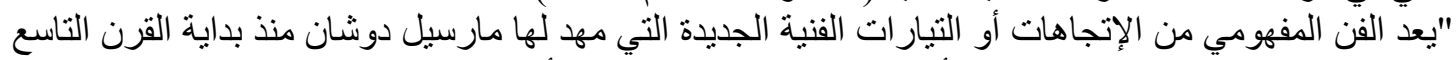

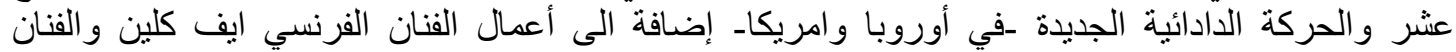

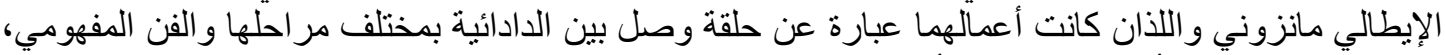

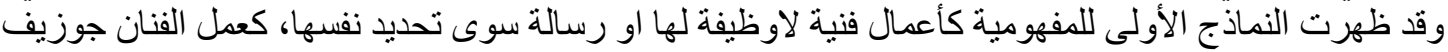

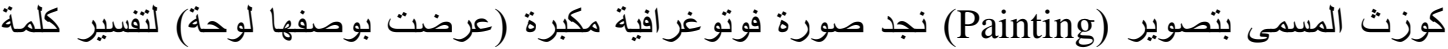
(Painting)

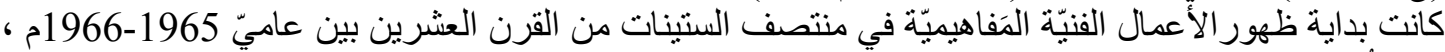

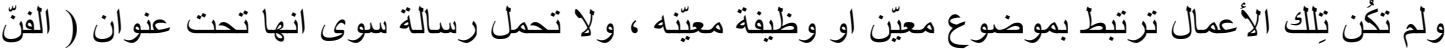

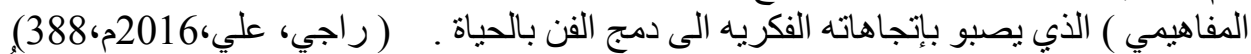

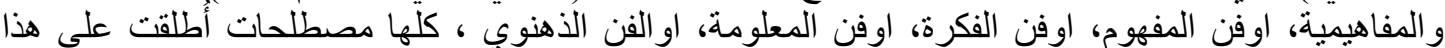

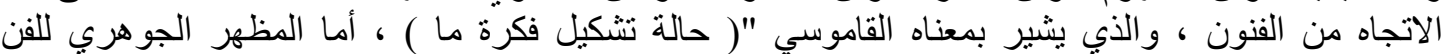

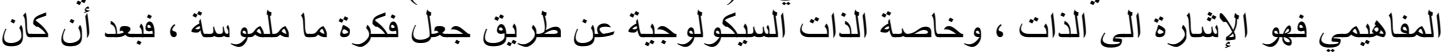

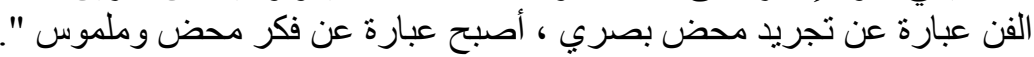

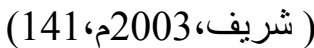

الفنان جوزيف كوزث (Joseph Kosuth) أحد رواد المراحل المبكرة من الفن المفاهيمي ، ان جميع الأعمال

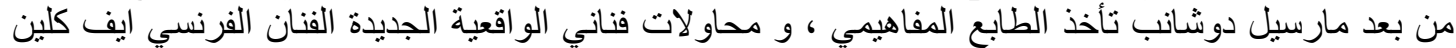

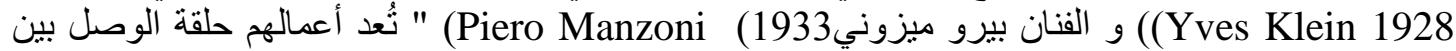

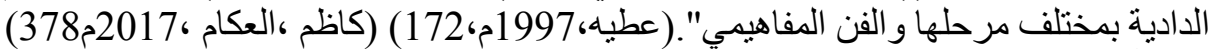

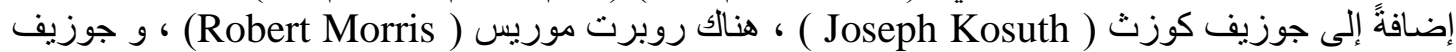
بويز ( Joseph beuys ) ، و ر رامسدن ميل ( Ramsden Mel) ، الروّاد الأكثر شهرة للفن المفاهيمي في

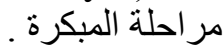




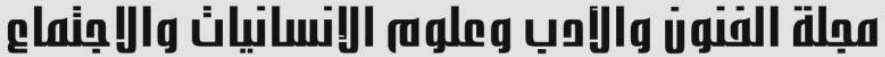

Journal of Arts, Literature, Humanities and Social Sciences www.jalhss.com

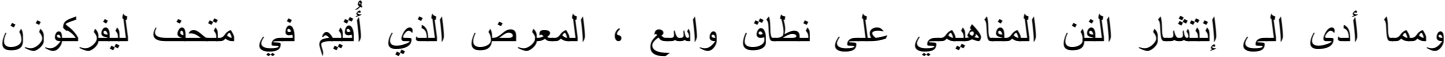
(conception ) ( ) ثم تبعة عدة معارض احدها (Leverkusen) في كولونبا عام 1974م ، ثم جانت في بلجيكا عام 1980م المبان ـ (عطيه، 1997م،174)

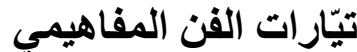

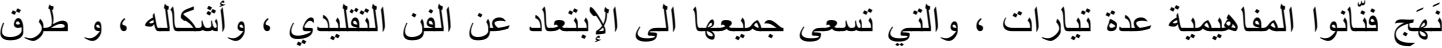

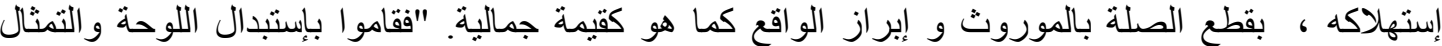

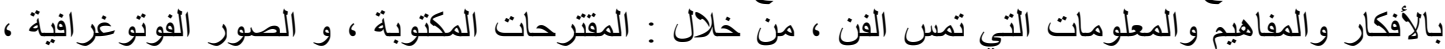

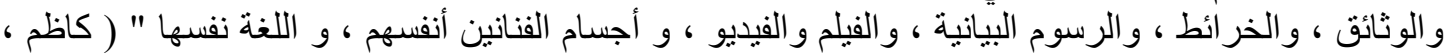

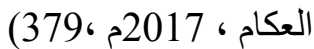

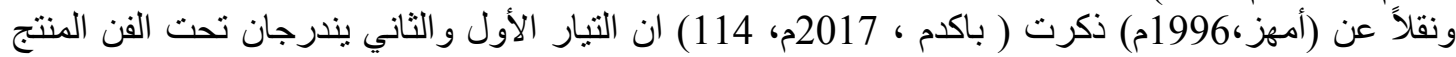

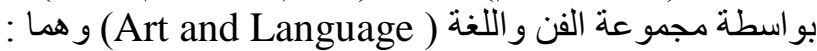

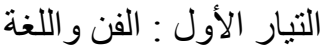

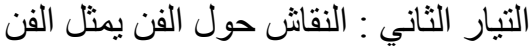
التيار الثالث : فن الأرض ( Earth Art ) التيار الر ابع : فن الجسد ( Body Art)

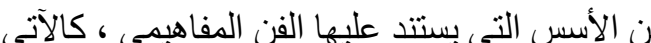

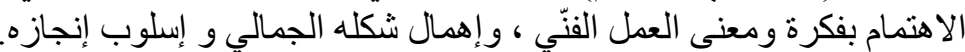
الخروج عن المألوف و السائد و التحرر من السلطة المهارية و الجمالية التقليدية ، بإستخدام التقنيات و الوسائط التقليدية و الجديدة. مشاركة المتلقي في بناء وتأسيس العمل الفنّي.

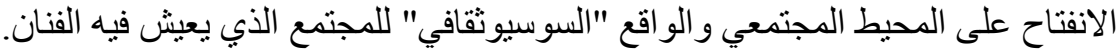

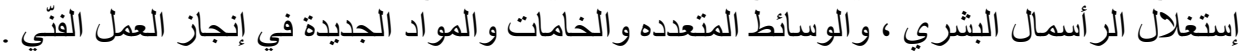

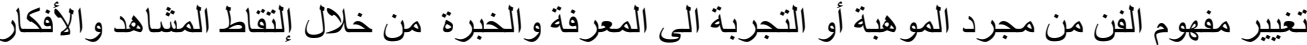
بو اسطة الوسائط و البر امج الإلكترونية الجديدة. بناء وتجميع الأعمال الفنيّة في الفراغ التونة سواء كانت ثلاثية الأبعاد او مسطحه ، من خلال إعادة تدوير المستهلكات و المو اد و الخامات المتعددة.

2- فن التجهيز في الفراغ ( Installation Art) تعددت المصطلحات التي أطلقت على هذا الإتجاه من فنون مابعد الحداثه ومن هذه المسميات : الاعمال المركبة،

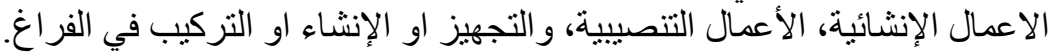

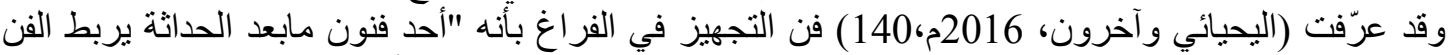

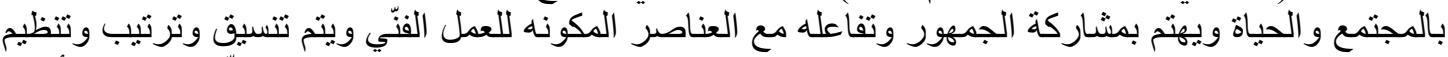

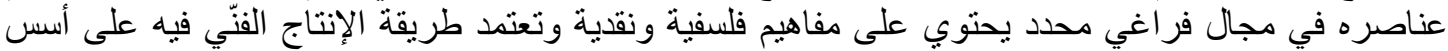
إنشائية وأساليب أدائية وتقنية، وتلعب البيئة و المكان و الوقت و الفر اغئ عناصر أساسية في إظهار شكل العمل الفني

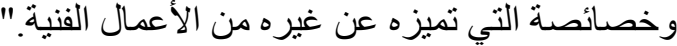

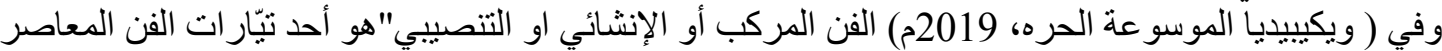

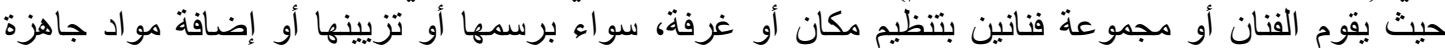
بوضعها أو بتعليقها في الفر اغ، ويستطيع المشاهد الدخول للمكان و التجول فيه كما لو كان جز أراً منه، وقد تتحرّك 


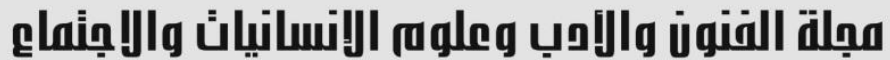

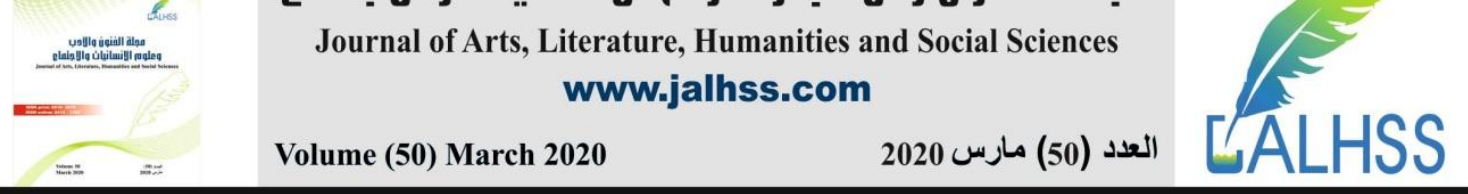

الأشياء الموجودة بالآلات أو بطرق أخرى، كما وقد نسمع موسيقى تساعد على التعبير عن الموضوع، ليكون هذا

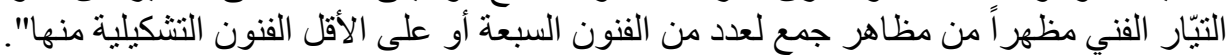

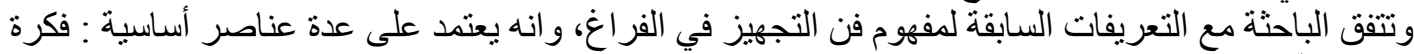

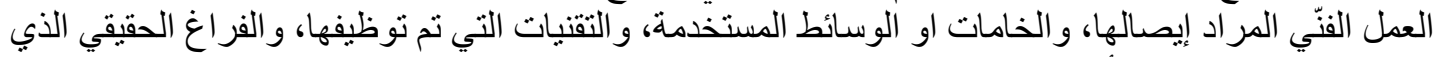
يدفع الجمهور للتنقل بين أجزاء العمل و التفاعل التفاعل معاها.

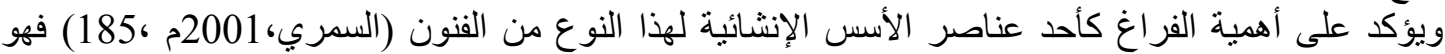

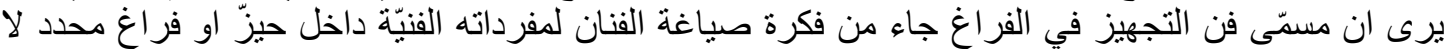

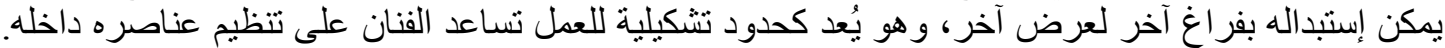

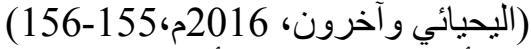
من أهم الفنانين الذين أبدعوا في مجال الفن المركب : راشيل وايتريد (Rachel Whiteread)، مارسيل

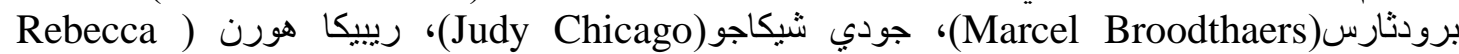

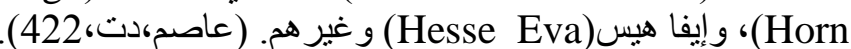

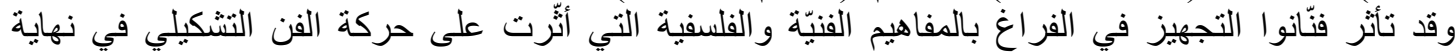

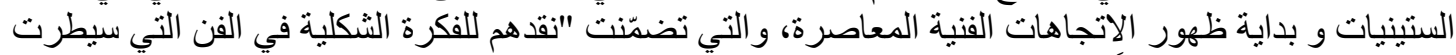

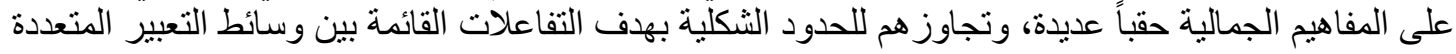

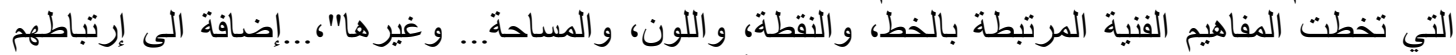

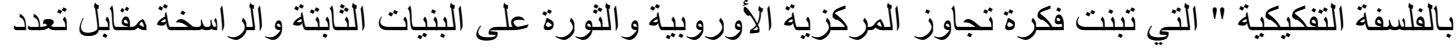

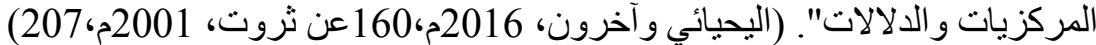

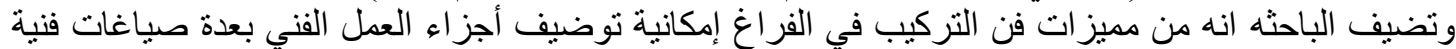

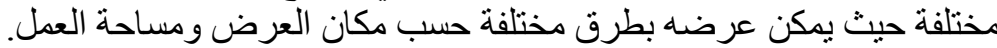

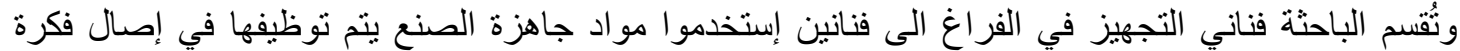

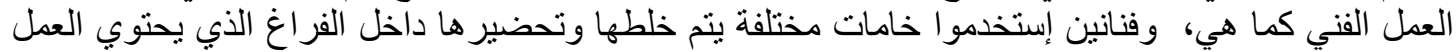
الفني ومن ثم تركيب أجز اء العمل وتختلف مدة الإنتهاء منه حسب حجم العمل الفني المجهز في الفر اغل الفي

\section{العناصر الأساسية التي يعتمد عليها العمل الفنّي المجزز في الفراغ}

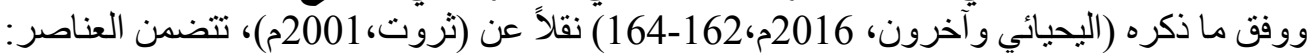

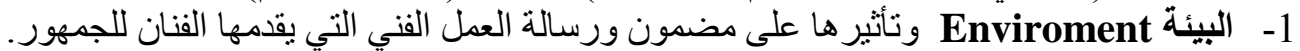

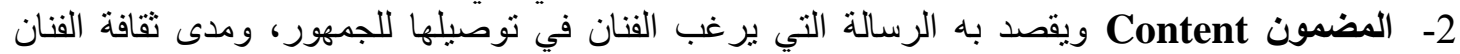

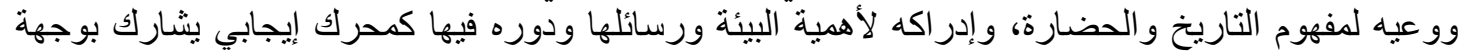

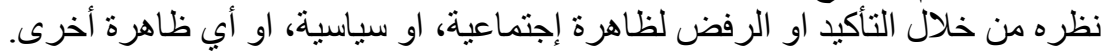

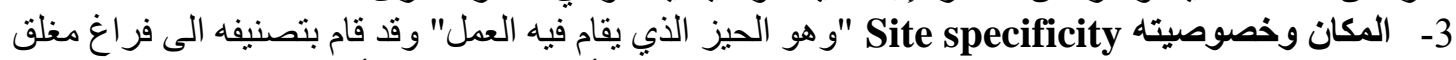

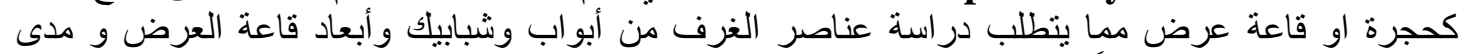

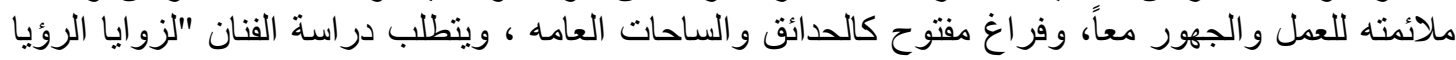

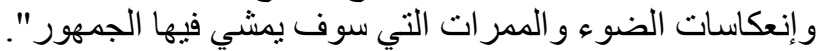

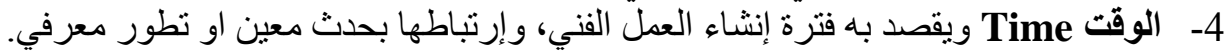

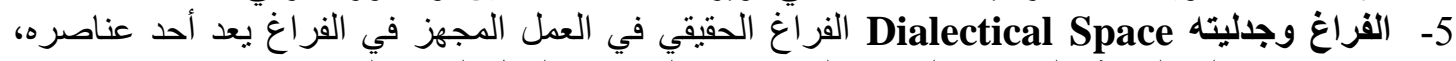

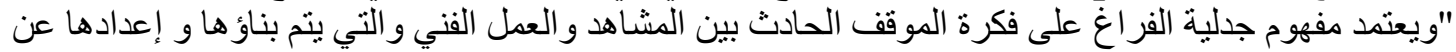

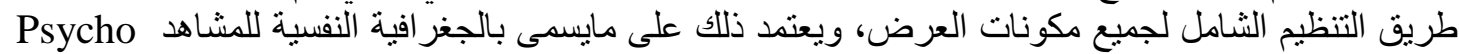

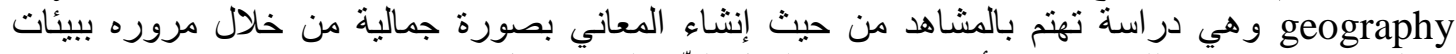

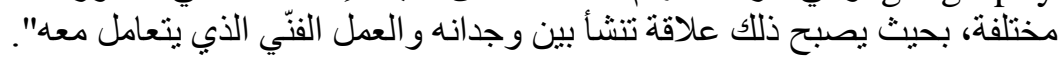

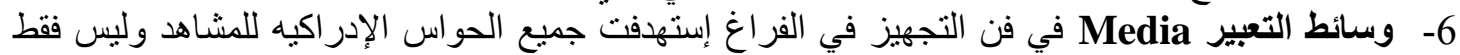
رؤية تأملية لتصبح العلاقة إدرأكيه حسيه وجدانية، وتنوع إستخدام فناني التجهيز في الفراغ الونيه لوسائط التعبير 


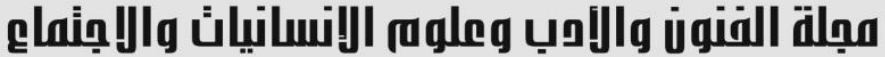

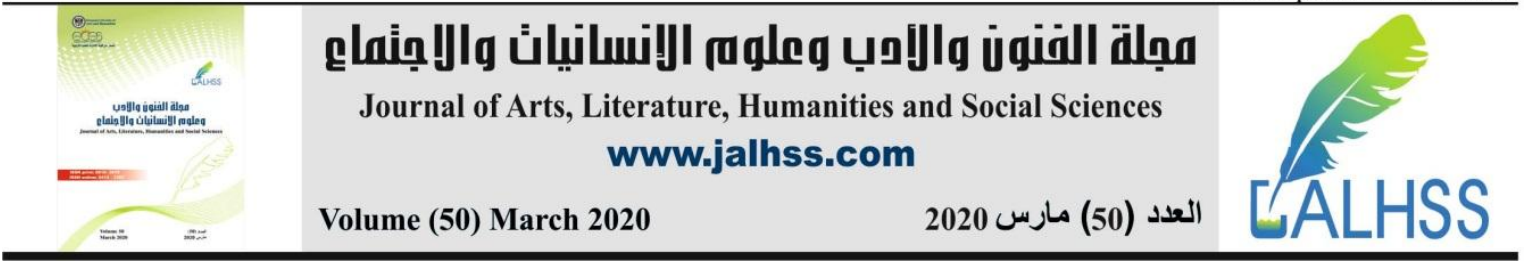

وتجاوزوا الحدود الفاصلة بين مجالات الفن التشكيلي، فإستخدموا الوسائط التكنولوجية، والوسائط العضوية،

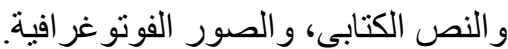
7- الجمهور الكي، Audience ويقصد بهم المشاهد او مستقبل العمل والذي عادةً مايكون جزءاً من العمل المجهز

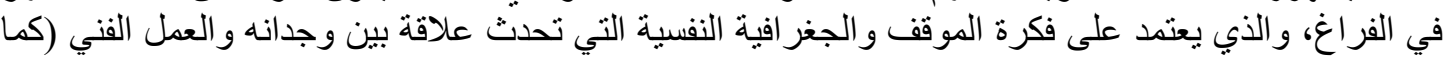

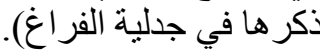

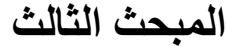 \\ تحليل أعمال فنية تثكيلية معاصرة تناولت مرض ألزهايمر}

تقوم الباحثة بإلقاء الضوء على بعض أعمال الفنانين التشكيلين المعاصرين الذين تناولو ا مرض ألزهايمر ، وتقوم الباحثه بتحليل الأعمال من خلال المحاور الهاور التالية: المحور الاول: هيئة العمل الفني معلقات ـ مجسمات ـ تكوين حر غير منتظم. لالفي الفئ

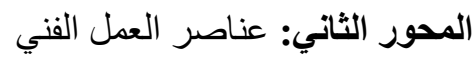

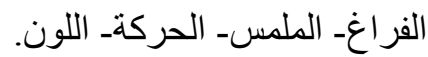

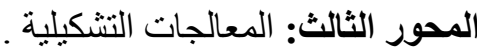

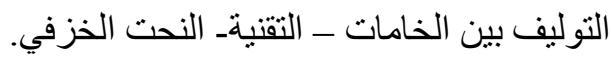
المحور الرابع: الإتجاهات الفنية التي نفذت بها الأعمال . الفن المفاهيمي - فن التجهيز في الفراغ. الفئ.

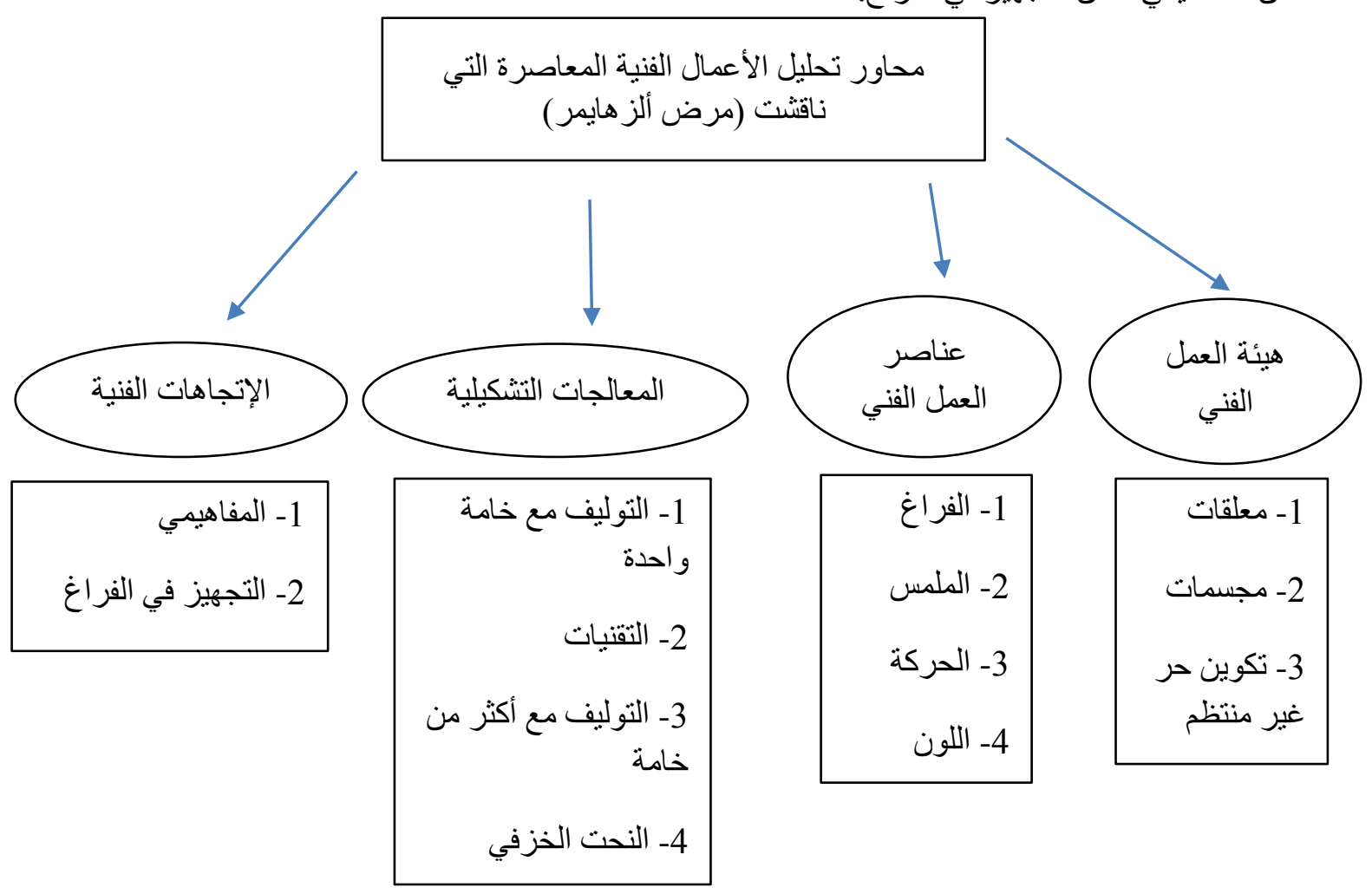

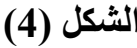




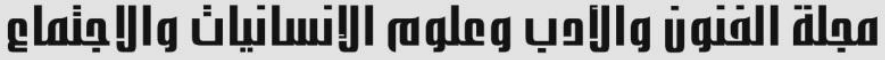

buss

Journal of Arts, Literature, Humanities and Social Sciences www.jalhss.com

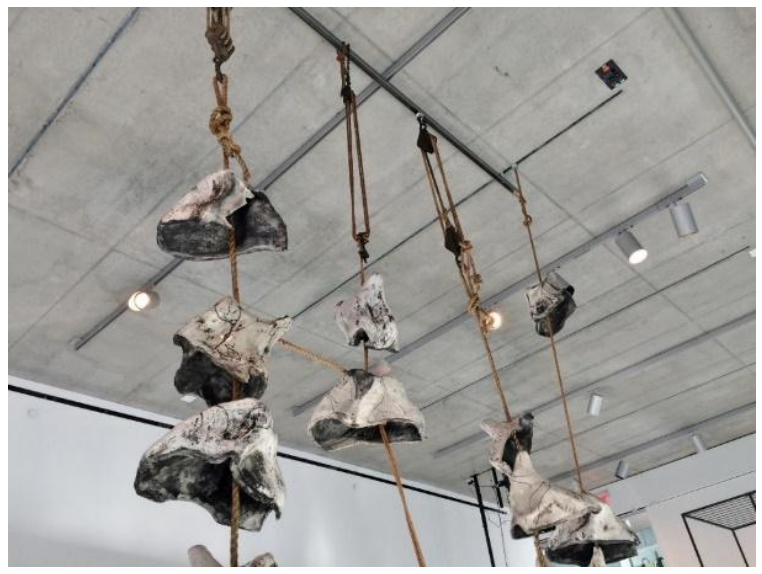

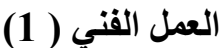

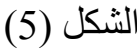

\begin{tabular}{|c|c|}
\hline 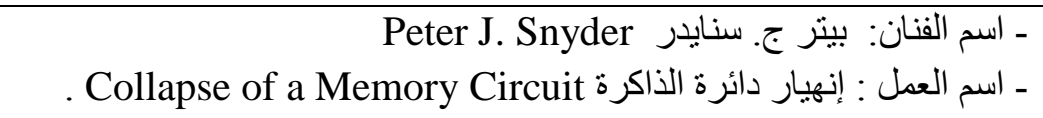 & بيانات العمل الفني \\
\hline نحت خزفي. & مجال العمل الفنّي \\
\hline 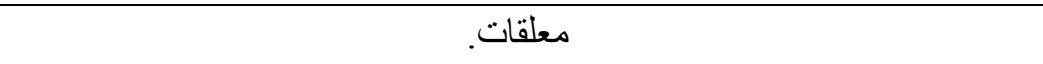 & هيئة العمل الفني \\
\hline توليف خامات خامة أساسية ( الخزف )، حبال قديمة، معدن- تقنيات. & المعالجات التشكيلية \\
\hline الفن الدفاهيمي+ فن التجهيز في الفراغ. & الاتجاهات الفنية \\
\hline 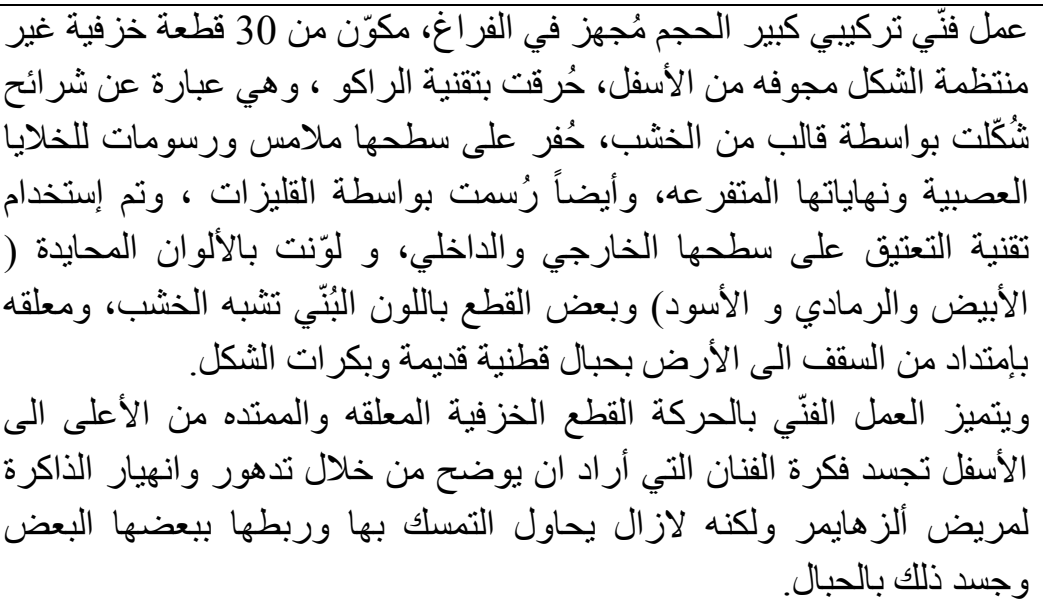 & وصف وتحليل العمل \\
\hline
\end{tabular}




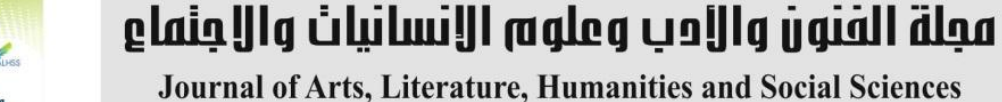
www.jalhss.com

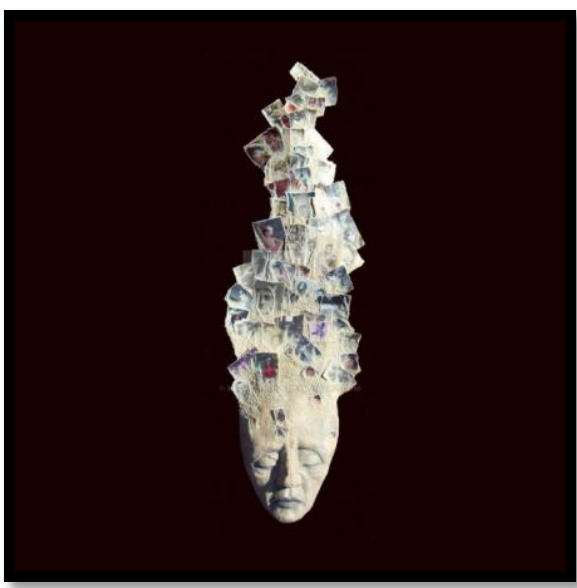

العمل الفني (2) - 2) - (2)

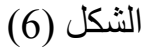

\begin{tabular}{|c|c|}
\hline 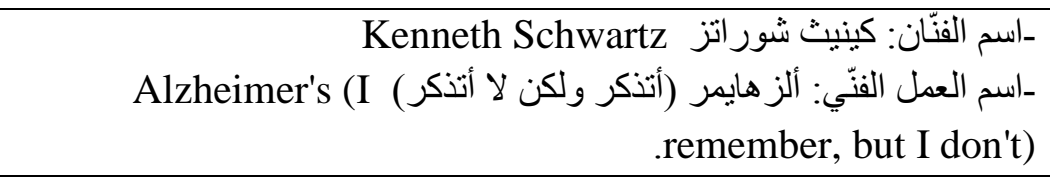 & بيانات العمل الفني \\
\hline نحت & مجال العمل الفنّي \\
\hline تكوين حر غير منتظم. & هيئة العمل الفني \\
\hline توليف خامات متعددة (أسلاك، عجينة الورق، أكريليك، رمل). - تقنيات. & المعالجات التشكيلية \\
\hline 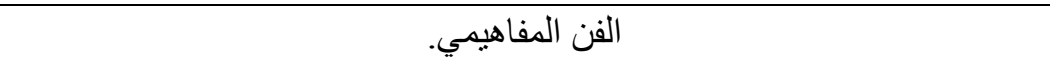 & الاتجاهات الفنية \\
\hline 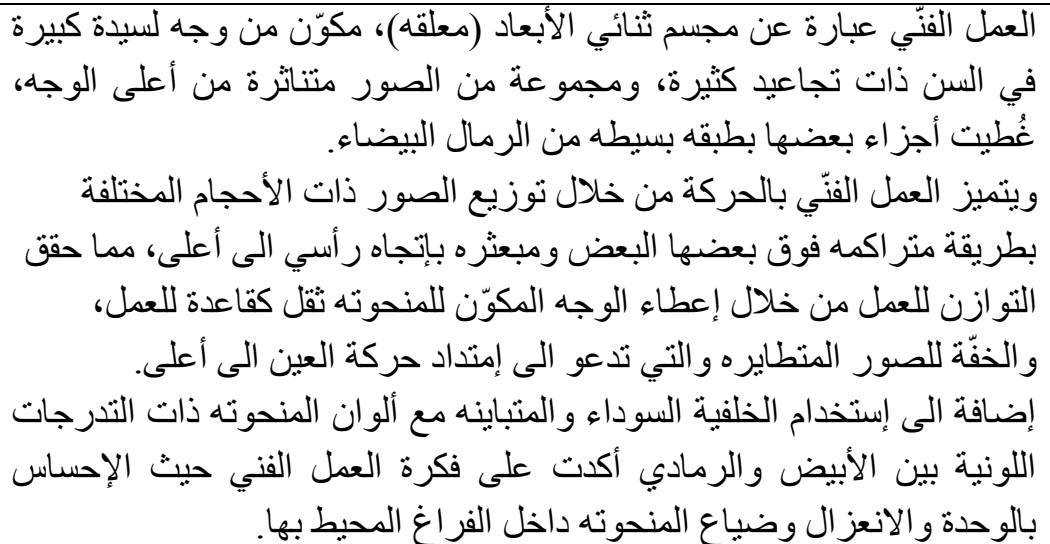 & وصف وتحليل العمل \\
\hline
\end{tabular}




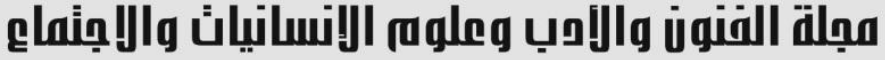

Journal of Arts, Literature, Humanities and Social Sciences www.jalhss.com
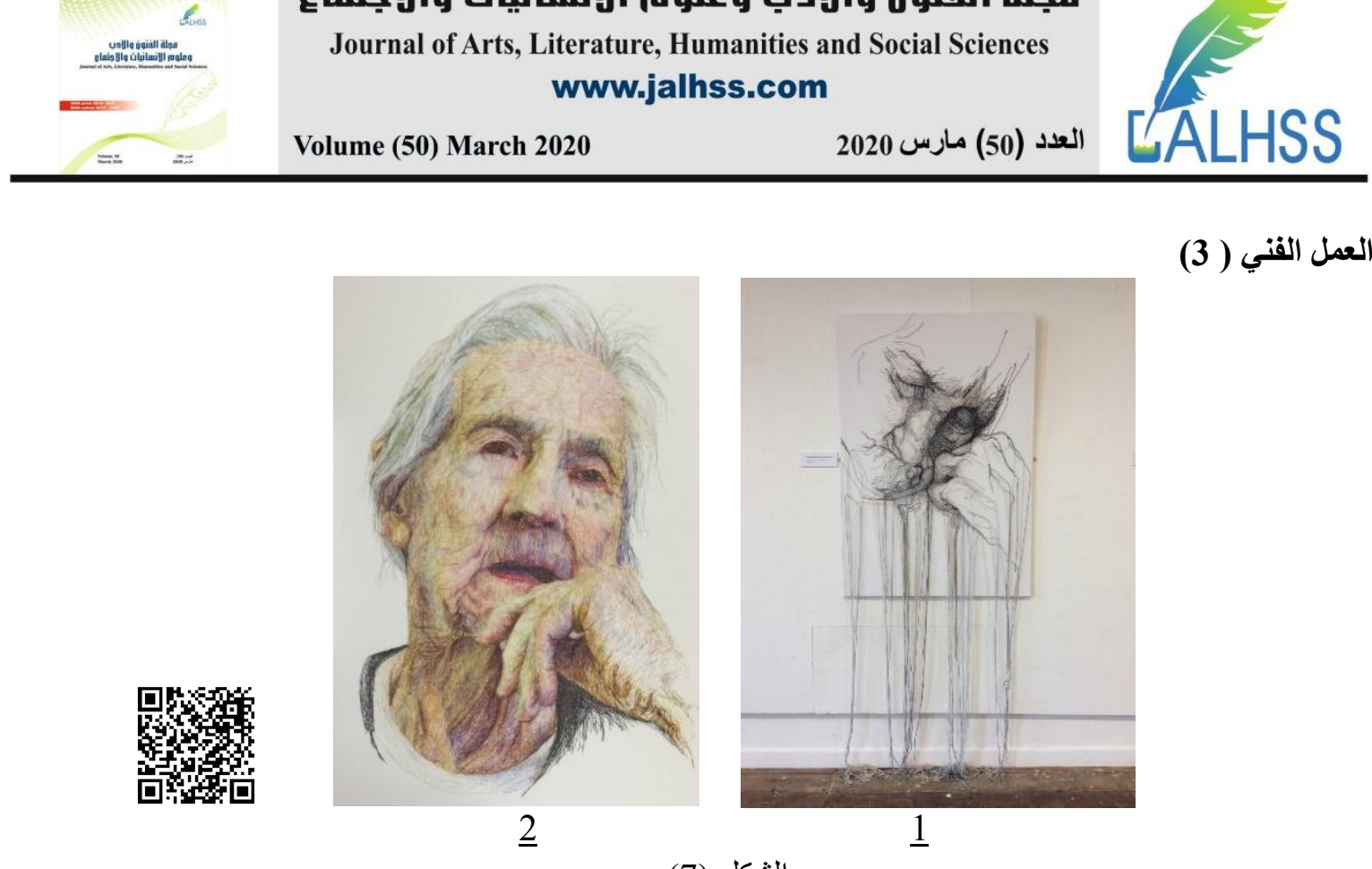

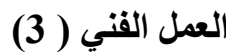

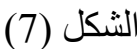

\begin{tabular}{|c|c|}
\hline 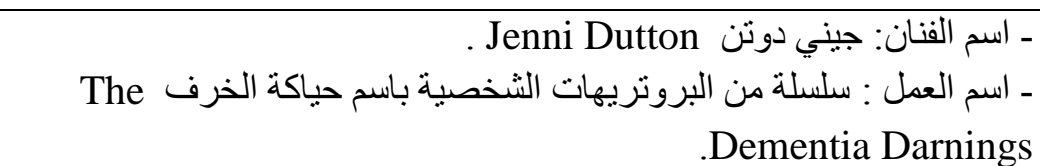 & مل الفني \\
\hline النسيج (تصوير البورتريهات). & الفّيّي \\
\hline معلقة & هيئة العم \\
\hline توليف خامات متنو عة خيوط مختلفة الألوان و السُمك - اقمشة كدعامه - إبر & المعالجات التشكيلية \\
\hline الفن المفاهيمي. & الاتجاهات الفنية \\
\hline 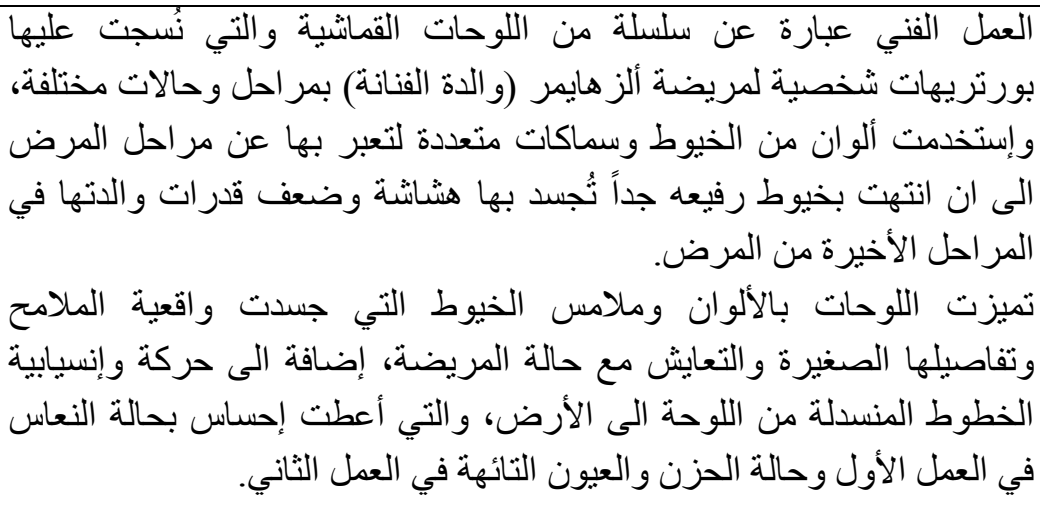 & وصف وتحليل العمل الفني \\
\hline
\end{tabular}




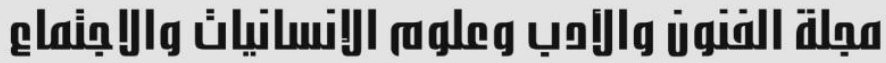

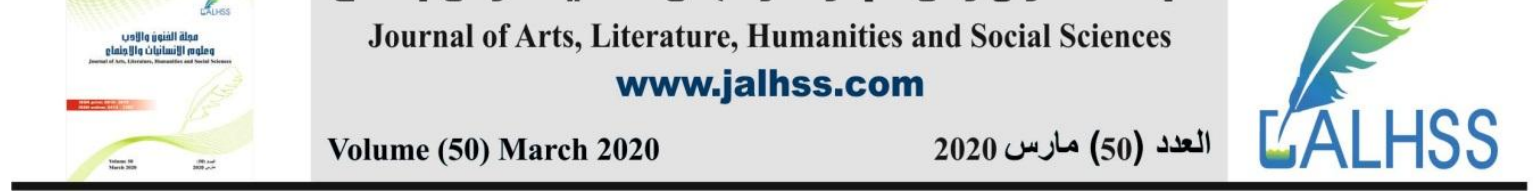

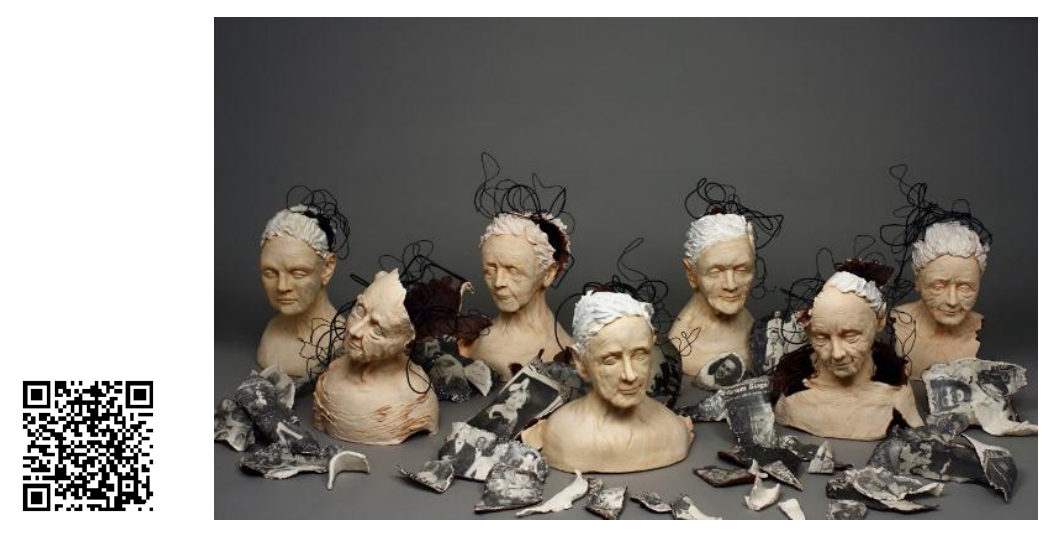

العمل القني (4)

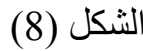

\begin{tabular}{|c|c|}
\hline 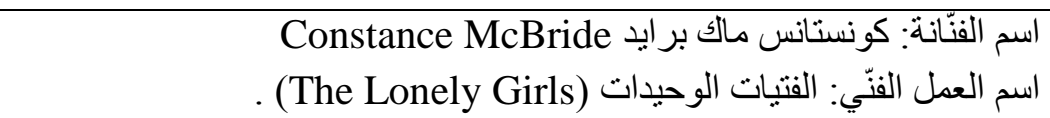 & بيانات العمل الفني \\
\hline 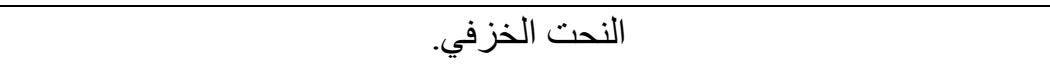 & مجال العمل الفنّي \\
\hline مجسمات. & هيئة العمل الفني \\
\hline توليف خامة الخزف مع المعدن، إستخذام تقنيات كالطباعة على الطينة. & المعالجات التشكيلية \\
\hline فن مفاهيمي، وتجهيز في الفراغ. & الاتجاهات الفنية \\
\hline 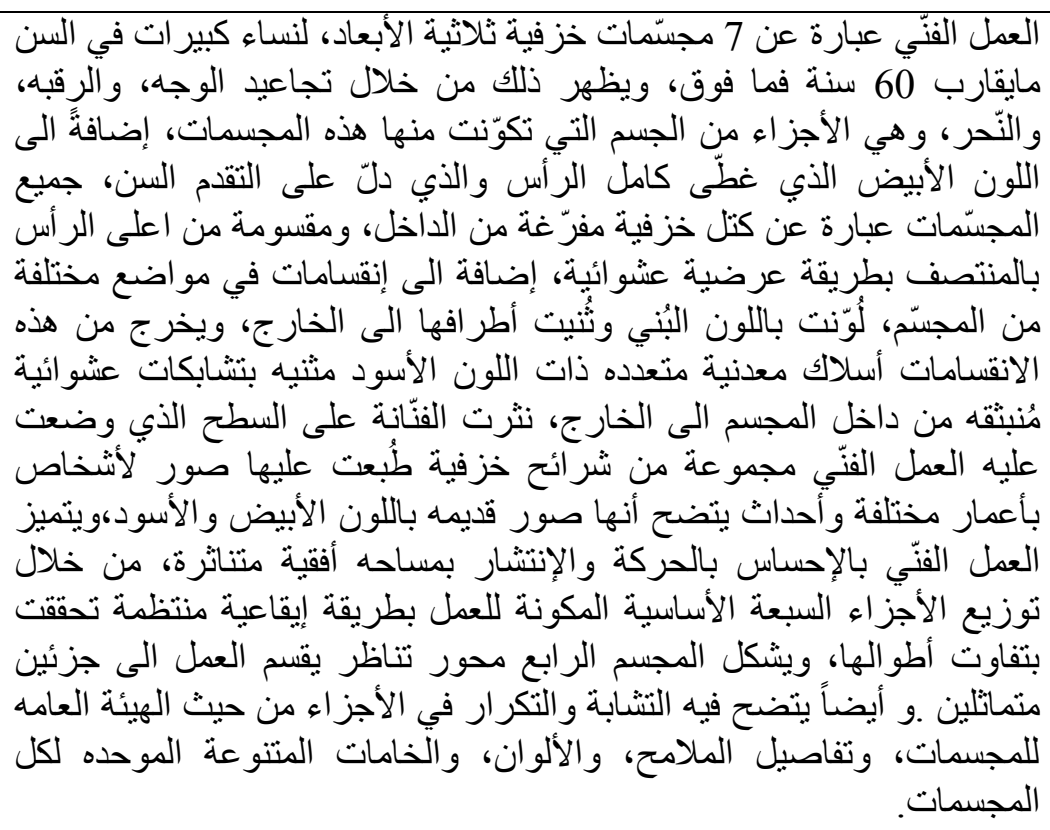 & وصف وتحليل العمل \\
\hline
\end{tabular}




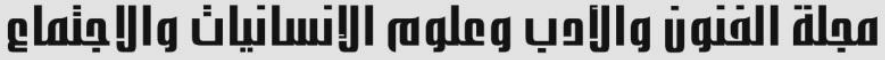

ISSN print: $2616-3810$

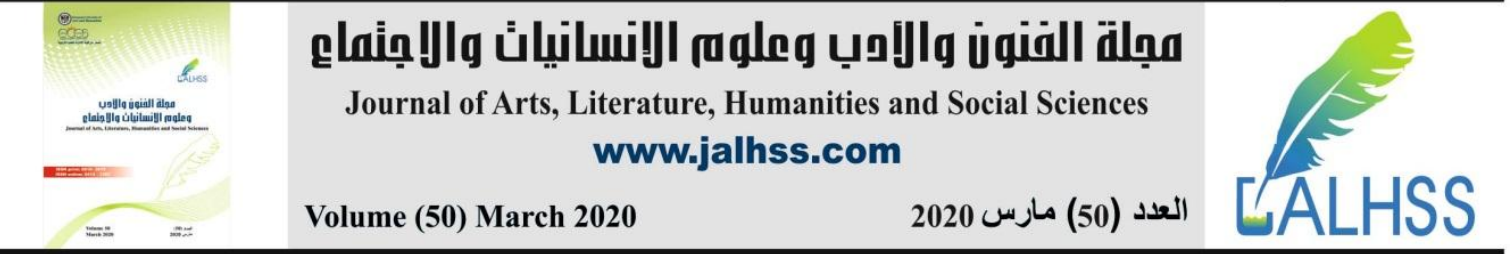

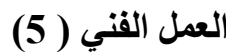

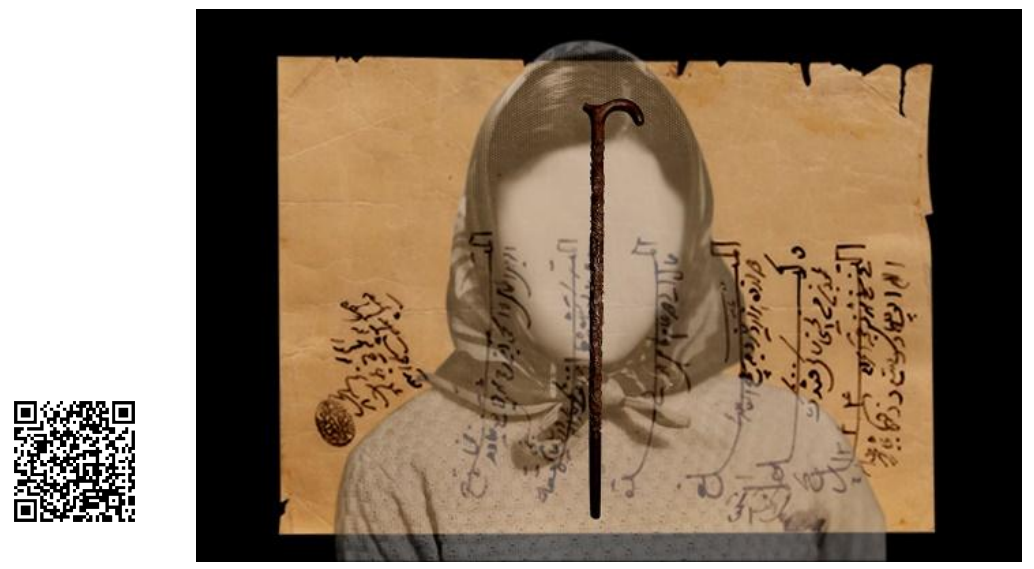

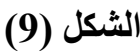

\begin{tabular}{|c|c|}
\hline ـ ـ اسم العمل: اللز هايمر. & بيانات العمل الفني \\
\hline تصوير فونوغر افي- بورتريه. & مجال العمل الفنّي \\
\hline معلقة. & هيئة العمل الفني \\
\hline ألو ان وتصوير رقمي على ورق. & المعالجات التشكيلية \\
\hline الفن المفاهيمي. & الاتجاهات الفنية \\
\hline 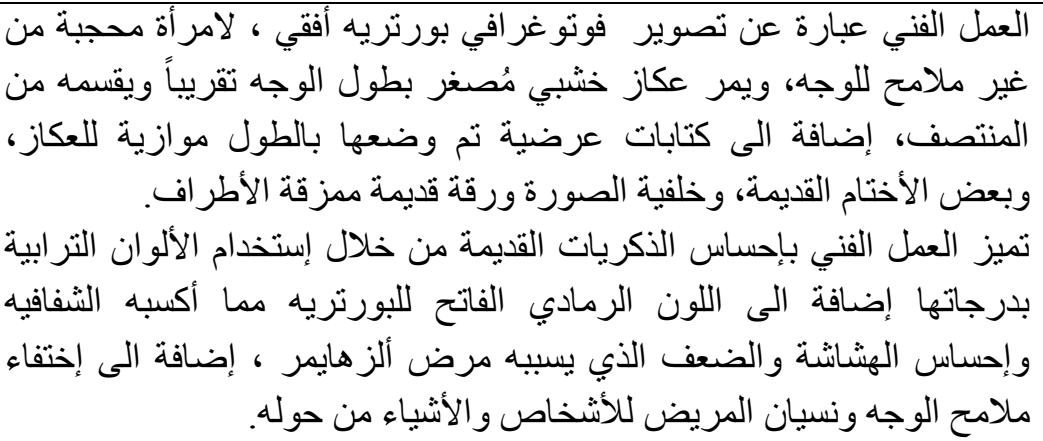 & وصف وتحليل العمل \\
\hline
\end{tabular}




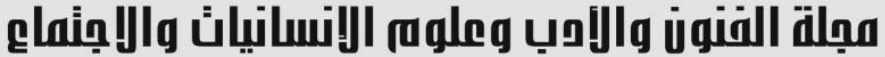

Journal of Arts, Literature, Humanities and Social Sciences www.jalhss.com

1- تميزت أعمال الفنانين المعاصرين بالقيم الفنية والجمالية المتعددة الناتجة من حداثه الفكر المفاهيمي

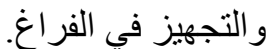

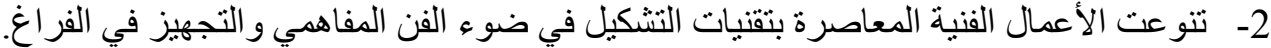
3- إتسمت الأعمال الفنية برؤى متعددة لتناول مرض ألز هايمر من حيث الفكر و الخامة و التعبير. ثوصيات البحث

1- المساهمة في رفع الثقافة البصرية لدى أفرد المجتمع من خلال مخاطبتهم بلغة التشكيل الفنّي المعاصر. 2- المساهمة في رفع الذائقة الفنيّة لدى أفر اد المجتمع من خلافل تذوقهم للأعمال الفنية التشكيلية المعاصرة التي تهدف إلى توعيتهم. 3- تكثيف الدر اسات التي تهنم بمساهمة التشكيل الفني المعاصر في القضايا الاجتماعية الصحيّة والتوعية

\section{الحواشي والثهوامش}

https://www.alz.co.uk/about-dementia .1 https://www.alz.org/facts/overview.asp .2 https://www.alz.org/alzheimers_disease_early_onset.asp .3 4. (AD): إختصنار لمرض ألزهايمر (Alzheimer's Disease) تكرر ذكره في الدراسات والمقالات الطبيّة التي

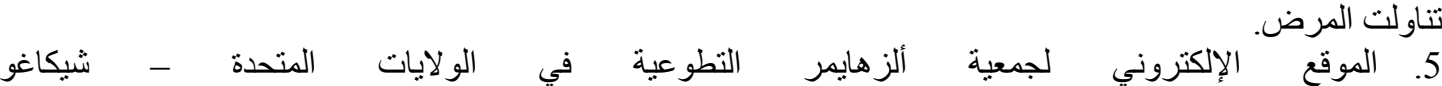
https://www.alz.org/alzheimers-dementia/what-is-alzheimers 6. https://www.alz.org/alzheimers-dementia/what-is-alzheimers/causes-and-risk-factors دخول 1440-10-14هـ

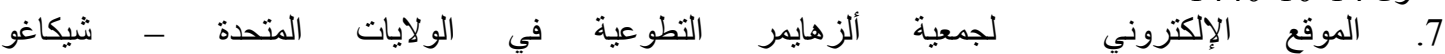
https://www.alz.org/alzheimers-dementia/what-is-alzheimers/younger-early-onset 8. 9 9 المرجع السابق. 10. ماريخ آخر دخول 16-10-10-//www.alz.co.uk/research/WorldAlzheimerReport2018.pdf

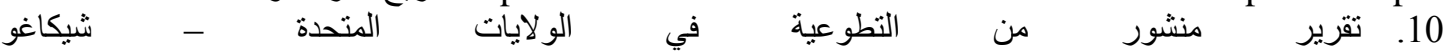
https://www.alz.org/media/Documents/alzheimers-facts-and-figures-infographic-2019.pdf تاريخ آخر دخول 16-10-10 1440هـ. http://www.alz.org.sa/wp-content/Upload- نقرير منشور للجمعية الخيرية السعودية لمرض ألزهايمر دارير reports/statistics.pdf

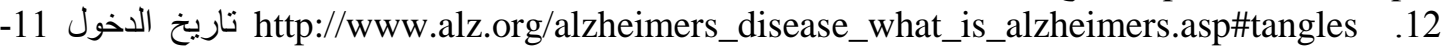
1439-1

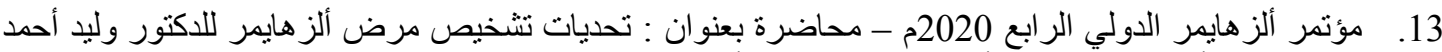

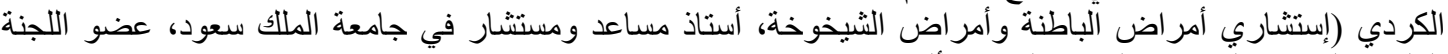

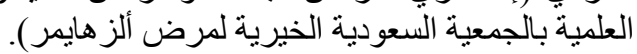

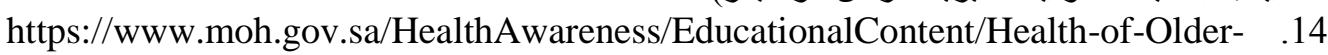
Persons/Pages/Alzheimer.aspx

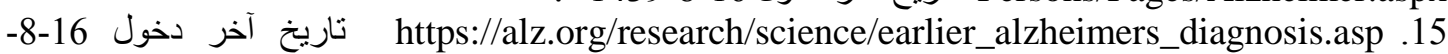
1439هـ https://ar.wikipedia.org/wiki/\%D9\%81\%D9\%86_\%D9\%85\%D8\%B9\%D8\%A7\%D8\%B5 .16 


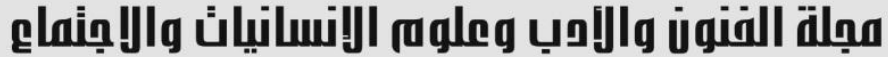

Journal of Arts, Literature, Humanities and Social Sciences www.jalhss.com

1. عاصم، ريم (د.ت) فنون مابعد الحداثة في الغرب_النشأه و التطور ، مجلة العمارة و الفنون ، العدد التاسع 407:426

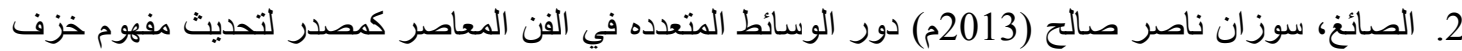
الأماكن المفتوحه، رسالة ماجستير غير منشورة، كلية الاقتصاد المنزلي، جامعة الماني الملك عبدالعزيز، جدة، المملكة العربية السعودية.

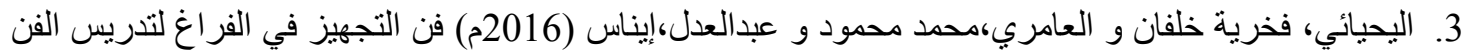
المعاصر في مقرر المشروع لطلبة جامعة السلطان قابوس ، مجلة جامعة ام القرى للعلوم التربوية و والنفسية ، المجلد للفي

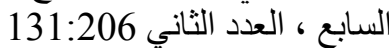
4. الهز اع، حنان سعود (2014م). إثكالية التلقي في الفن السعودي المعاصر "بين المحلية والعالمية" مجلة التصميم الدولية، المجلد الرابع، العدد (3). يوليو 89 - 801 -101 .

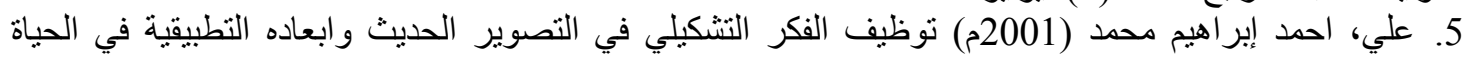

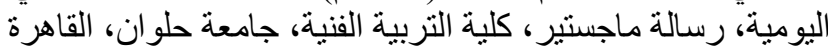

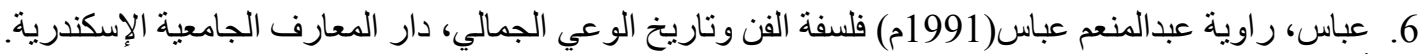

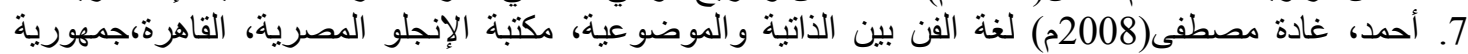

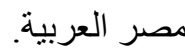
8. الرصيص، محمد (2010 ) تاريخ الفن التشكيلي في المملكة العربية السعودية، الرياض، وزئة وزارة الثقافة والإعلام.

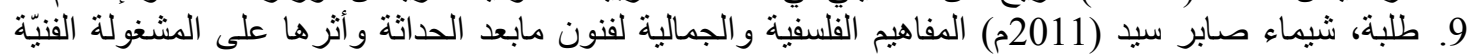

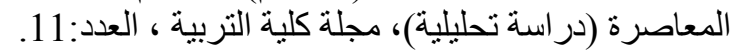

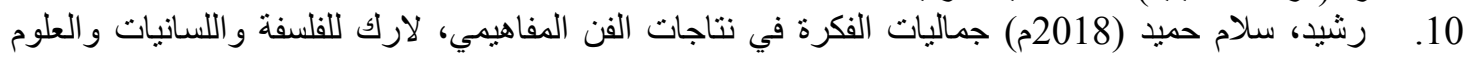

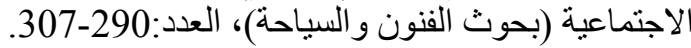

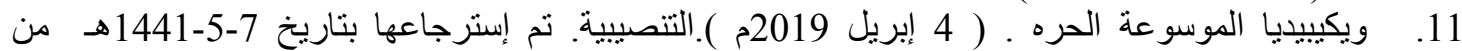
https://ar.wikipedia.org/wiki/\%D8\%AA\%D9\%86\%D8\%B5\%D9\%8A\%D8\%A8\%D9\%8A $\% \mathrm{D} 8 \% \mathrm{~A} 9$ 12. الموقع الإلكتروني لجمعية ألزهايمر التطوعية في الولايات المتحدة - شيكاغو. نم إسترجاعها بتاريخ تاريخ

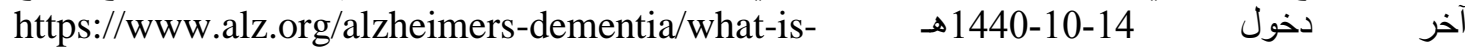
alzheimers/younger-early-onset 13. أبو حامد، سمير (2009م) مرض الزهايمر "النسيان من نعمة إلى نقمة"،خطو ات للنشر و التوزيع، دمشق.

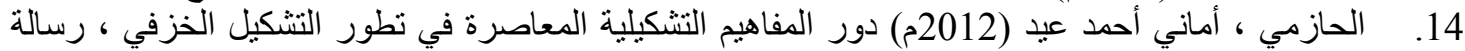

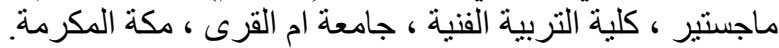

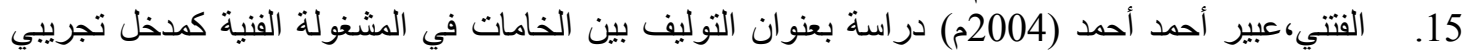
إبتكاري يستند الى التكنولوجيا المعاصرة ، رسالة ماجستير ، كلية التربية للإقتصناد المنزلي و التربية الفنية، جامعة الفية الملك عبدالعزيز ، جدة. 16. الياسري، صبا قبس (2011م) در اسة بعنوان الفن ودوره الاجتماعي و التربوي و إمكانية التفعيل في 17.

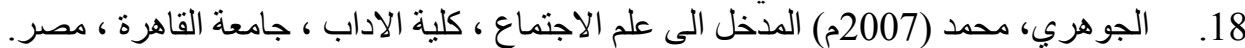

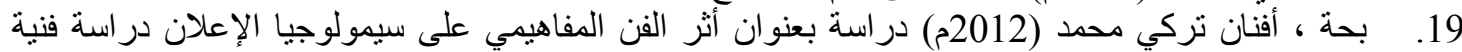

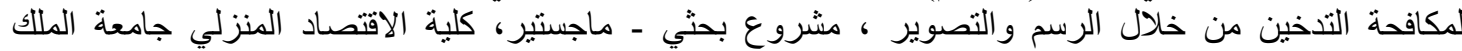

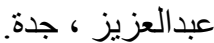
20. باجمال ، مها حسين (2014م) دراسة بعنوان القضايا الاجتماعية في الفن التشكيلي السعودي المعاصر، رسالة ماجستير ، كلية التربية الفنية ، جامعة ام القرى ، مكة المكرمة . 


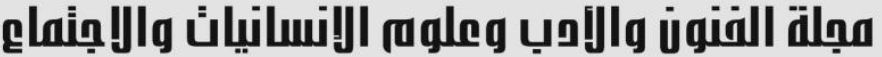

Journal of Arts, Literature, Humanities and Social Sciences www.jalhss.com

\section{References}

1. Assem, Reem (N.D.) Postmodernist arts in the West - evolution and evolution, Journal of Architecture and Art, ninth issue 407: 426.

2. Al-Sayegh, Susan Nasser Saleh (2013) The Role of Multimedia in Contemporary Art as a Source for Modernizing the Concept of Open Space Ceramics, Unpublished Master Thesis, College of Home Economics, King Abdulaziz University, Jeddah, Saudi Arabia.

3. Al-Yahyai, Fakhriya Khalfan and Al-Amri, Muhammad Mahmoud and AbdulAdil, Enas (2016 AD) The Art of Preparation in the Void for Teaching Contemporary Art in the Project Course for Sultan Qaboos University Students, Umm Al-Qura University Journal for Educational and Psychological Sciences, Volume VII, Second Issue 131: 206

4. Al-Hazaa, Hanan Saud (2014). The problem of receiving in contemporary Saudi art "between local and international" International Design Magazine, Volume IV, No. (3). July 89 -101.

5. Ali, Ahmed Ibrahim Mohamed (2001) Employment of plastic art in modern photography and its applied dimensions in daily life, Master Thesis, Faculty of Art Education, Helwan University, Cairo

6. Abbas, Rawia Abdel Moneim Abbas (1991 AD), Philosophy of Art and Aesthetic Awareness History, University of Alexandria Knowledge House.

7. Ahmed, Ghada Mostafa (2008 AD) The Language of Art between Subjectivity and Objectivity, The Egyptian Anglo Library, Cairo, Arab Republic of Egypt.

8. Al-Rasis, Muhammad (2010) History of Fine Art in the Kingdom of Saudi Arabia, Riyadh, Ministry of Culture and Information.

9. Students, Shaimaa Saber Sayed (2011). Philosophical and aesthetic concepts of postmodern arts and its impact on contemporary artistic work (analytical study), Journal of the College of Education, Issue: 11.

10. Rashid, Salam Hamid (2018 AD) Aesthetics of Idea in the Outcomes of Conceptual Art, Lark for Philosophy, Linguistics and Social Sciences (Arts and Tourism Research), Issue: 290-307.

11. Wikipedia the free encyclopedia . (April 4, 2019). Retrieved on 7-5-1441 AH from

https://ar.wikipedia.org/wiki/\%D8\%AA\%D9\%86\%D8\%B5\%D9\%8A\%D8\%A8\%D 9\%8A\%D8\%A9

12. The website of the United States Alzheimer's Volunteer Association Chicago. Retrieved on the date of last entry 10-14-1440 AH https://www.alz.org/alzheimers-dementia/what-is-alzheimers/younger-early-onset 13. Abu Hamed, Samir (2009 AD) Alzheimer's disease "Forgetting from a blessing to a curse", steps for publication and distribution, Damascus.

14. Al-Hazmi, Amani Ahmed Eid (2012 AD) The Role of Contemporary Fine Concepts in the Development of Ceramic Formation, Master Thesis, College of Art Education, Umm Al-Qura University, Makkah Al-Mukarramah. 


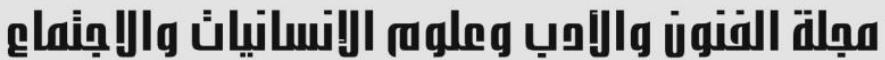

Journal of Arts, Literature, Humanities and Social Sciences www.jalhss.com

15. Al-Fatni, Abeer Ahmed Ahmed (2004), a study entitled Synthesis of raw materials in artistic works as an innovative experimental approach based on contemporary technology, Master Thesis, College of Education for Home Economics and Art Education, King Abdulaziz University, Jeddah.

16. Al-Yasiri, Saba Qais (2011), a study entitled Art and its social and educational role and the possibility of activation in

17. Arab Societies, published scientific research, Journal of the Kufa Studies Center, No. 21: 65-88.

18. El-Gohary, Mohamed (2007 AD) Introduction to Sociology, Faculty of Arts, Cairo University, Egypt.

19. Baha, Afnan Turki Muhammad (2012), a study titled "The Impact of Conceptual Art on Advertising Simology: An Artistic Study to Combat Smoking through Drawing and Painting," Research Project - Master, College of Home Economics, King Abdulaziz University, Jeddah.

20. Bajammal, Maha Hussein (2014), a study entitled Social Issues in Contemporary Saudi Plastic Art, Master Thesis, College of Art Education, Umm AlQura University, Makkah Al-Mukarramah.

21. -Alzheimer's Association Report ( 2017) Alzheimer's disease facts and figures, Alzheimer's \& Dementia ,13: 325-373.

22. Alzheimer's Association (2017) Alzheimer's disease facts and figures , 27-1$2018 \mathrm{https}: / / \mathrm{www}$.alz.org/facts/overview.asp.

- Alzheimer's Disease International (ADI) 27-1-2018 https://www.alz.co.uk/aboutdementia

23. Alzheimer's Association

$11-2-2018$

https://www.alz.org/alzheimers_disease_early_onset.asp 